\title{
Features, Syntax, and Categories in the Latin Perfect
}

\section{David Embick}

\begin{abstract}
The analysis centers on the notion of category in synthetic and analytic verbal forms and on the status of the feature that determines the forms of the Latin perfect. In this part of the Latin verbal system, active forms are synthetic ("verbs") but passive forms are analytic (i.e., participle and finite auxiliary). I show that the two perfects occur in essentially the same structure and are distinguished by a difference in movement to $\mathrm{T}$; moreover, the difference in forms can be derived without reference to category labels like "Verb" or "Adjective" on the Root. In addition, the difference in perfects is determined by a feature with clear syntactic consequences, which must be associated arbitrarily with certain Roots, the deponent verbs. I discuss the implications of these points in the context of Distributed Morphology, the theory in which the analysis is framed.
\end{abstract}

Keywords: syntax/morphology interface, category, features, passive voice, Distributed Morphology

\section{Introduction}

Questions surrounding the relationship between syntactic and morphological definitions of category have played and continue to play an important role in grammatical theory. Similarly, issues concerning the type, nature, and distribution of features in different modules of the grammar define a number of questions in linguistic theory. In this article I examine the syntactic and morphological processes and features at play in the construction of analytic and synthetic verbal forms, and in the determination of different surface categories. I focus primarily on the fact that the Latin perfect is synthetic in the active voice (e.g., amāvi 'I (have) loved') but analytic in the passive, with a participial form of the main verb and a form of the auxiliary 'be' (amätus sum). Theoretically, the analysis addresses (a) the status of category in syntax and morphology, and (b) the status of the feature underlying the analytic/synthetic difference.

Beginning with category, the notion " participle," which plays a central role in the discussion of analytic verb forms, has a dual status: on one level defined morphologically ("verb that agrees

I would like to thank Morris Halle, Alec Marantz, and Rolf Noyer for numerous detailed discussions of this material. In addition, I have benefited from comments at various stages from Elena Anagnostopoulou, Karlos Arregi, Rajesh Bhatt, Jonathan Bobaljik, Noam Chomsky, Paul Elbourne, Martin Hackl, Sabine Iatridou, Liina Pylkkanen, Norvin Richards, Don Ringe, and Philippe Schlenker. Parts of this article were also presented at the Second Penn/MIT Workshop on the Lexicon, and I would like to thank the workshop participants and members of the audience for additional comments. Finally, I would like to thank the JST/MIT [Mind Articulation] Project for support during the time that the research presented here was conducted. 
in the 'adjectival' pattern'), on another level defined in terms of syntactic distribution ("verb appearing (in certain contexts) with a finite auxiliary and with certain morphosyntactic features, etc."). Underlying these types of definitions is the intuition that a participle may be defined as a verb behaving in some sense nonverbally. In traditional terms, this is akin to the classification of a participle as a type of (or as related to) a "deverbal adjective," that is, as part nominal ( = adjectival), part verbal. ${ }^{1}$ Classifications of this type lead naturally to the position that participles are in some sense "derived" as opposed to "primitive," but do not illuminate the nature of the derivation.

In the abstract, we may consider two possible types of analysis in which a V(erb) is realized as a participle. The first sees an underlying $\mathrm{V}$ as being of necessity converted into the category A(djective). On this view the designations $V$ and $A$ have substantive content, in that they are associated with both syntacticosemantic and morphological effects. For instance, the morphological properties of the derived A differ from those of the original $\mathrm{V}$, in that it would show gender/number/case distinctions; at the same time, properties such as Case assignment might also be different in the derived $\mathrm{A}$ than in the original V. Whatever the particulars of the categorychanging operation are (i.e., whether it takes place in a lexicon, or by virtue of a syntactic AP dominating a VP), the result is the same: a clause containing the participle is distinct from one in which "regular" verbs are found.

The second alternative is that the syntax of participles does not involve an "adjectivalizing" projection AP above VP, or any lexical operation; instead, the category change from V to A is only relevant after the syntactic derivation. This is the type of approach that I develop here. The basis for this is an argument showing that the same syntactic structure underlies both auxiliary + participle formations and finite verbs in the perfect. That is, the two types of perfect appear in the same syntactic structure and differ only in the position to which the verb has raised in the tree. This treatment has clear implications for the notion of category: different morphological categories are realized in the two perfects, but the syntactic structure from which they are derived is the same. Thus, the difference in morphological category does not correspond to a difference in syntactic category. Against this background, the syntactic distribution and morphological behavior of "past passive participles" found in the perfect is shown to follow directly from the syntactic derivation and independently required properties of Latin morphology. No category-changing syntactic position is needed to derive the participial form-its appearance and behavior follow from general procedures operating on a specific syntactic structure. Rather than being "adjectives derived from verbs,' " participles result from the realization of label-neutral Roots in a configuration that has components associated with finite verbs, but that differ in crucial respects to be made explicit below. ${ }^{2}$

${ }^{1}$ Thus, for instance, in classical grammar, the source of the Latin term participium is to be found in the fact that participles behave in part like verbs, expressing temporal/aspectual distinctions, and in part like nouns, varying for case. See Varro 1938:VIII 58/X 17.

2 Theories employing Roots underspecified in this manner are advanced in Marantz 1995, 1997, developing ideas from Chomsky 1970; additional details of this approach will be made clear below. 
The arguments I develop are presented in the context of a particular conception of modularity in the grammar. In order to make this clear, I will first review some basic properties of Distributed Morphology (Halle and Marantz 1993 and related work), the theory in which the analysis is framed. Distributed Morphology operates in terms of Late Insertion, the idea that phonological pieces instantiate terminals containing abstract features postsyntactically, with the syntax proper manipulating sets of features. ${ }^{3}$ I will refer to the actual pieces of phonological material as exponents. These exponents, along with a statement of the features they instantiate, are vocabulary items. Particular vocabulary items compete for insertion into morphosyntactic positions, with the item most highly specified for the features on a node taking precedence over less-specified items; this is disjunctive realization, as in Anderson 1986, 1992. Defined in terms of positions, this is in accordance with the Subset Principle, such that the vocabulary item specified for the greatest subset of features on a terminal will be inserted into that position.

\section{(1) Subset Principle}

The phonological exponent of a vocabulary item is inserted into a position if the item matches all or a subset of the features specified in the terminal morpheme. Insertion does not take place if the vocabulary item contains features not present in the morpheme. Where several vocabulary items meet the conditions for insertion, the item matching the greatest number of features specified in the terminal morpheme must be chosen. (Halle 1997:427)

A further background assumption concerns the distinction between the functional and lexical vocabularies of a language. I will assume that functional categories merely instantiate sets of abstract syntacticosemantic features. Thus, notions like "determiner," "tense," and so on, are definable in terms of these features. The open-class (lexical) vocabulary items, referred to as Roots, are not simply the realizations of feature bundles. They consist of phonological representations, which have encyclopedic (i.e., not purely featural) meanings. ${ }^{4}$ What other content they possess-for instance, whether they are specified for syntactic category or for semantic features-is precisely what is at issue.

According to a further hypothesis, expressed in Marantz 1994, 1995, Roots too are subject to Late Insertion; that is, they are only inserted into syntactic structures in the morphological component, like functional vocabulary items. ${ }^{5}$ This position on modularity makes specific predictions about the flow of information between components of the grammar. Specifically, in the simplest case arbitrary features of vocabulary items could not affect the syntax, because the

${ }^{3}$ The position that morphosyntactic and morphophonological features are distinct from one another is not unique to Distributed Morphology; it is the instantiation of the Separation Hypothesis (named by Beard (1966)) and is assumed in a number of other frameworks. Differences between Distributed Morphology and other separationist theories will be taken up in section 8 .

${ }^{4}$ See Harley and Noyer 1998 for a discussion of some of the consequences of the differences in vocabulary types.

${ }^{5}$ Or, positions that have been added to this structure in the morphology; see below. 
vocabulary items are not present in the syntax. With its converse, this position is stated in the notion of Feature Disjointness, defined as follows:

\section{(2) Feature Disjointness}

Features that are phonological, or purely morphological, or arbitrary properties of vocabulary items, are not present in the syntax; syntacticosemanticfeatures are not inserted in morphology.

This position is a clear consequence of the hypothesis that Late Insertion is universal, that is, applies in all possible cases, to functional morphemes and Roots alike. The resulting view of features is based on the following reasoning. Particular Roots and functional vocabulary items are not present in the syntactic computation. This has the effect of imposing a distinction among the types of features that are found in syntax and morphology. Feature Disjointness is a strong hypothesis about how features in the grammar will interact; and, to the extent that it is valid, it follows directly from the structure of the grammar outlined above. In effect, it makes a particularly strong claim concerning the hypothesis of Late Insertion.

The aspect of this position on features that is relevant for the present discussion is the idea that features that are the idiosyncratic properties of particular Roots are not present in the syntactic derivation. Conjugation and declension class features, which are simply memorized with particular nouns or verbs, are clear examples of features of this kind; although they are required for morphological well-formedness in languages like Latin, they have no syntactic status. Similarly, phonological properties of Roots (e.g., 'begins with /s/-') ) seem to be irrelevant for the syntax.

The type of argument that can be made in this framework is then straightforward. If it can be shown that a feature is an arbitrary property of a Root, and that the same feature figures crucially in some process, then the conclusion that should follow is that the feature and the process in question are morphological (i.e., not present in the syntactic computation). In the case I examine here, however, the feature found to be responsible for the forms of the Latin perfect is shown to be (a) an arbitrary property of certain Roots, and (b) a feature that figures crucially in a syntactic process. The implication is that the feature in question has to be present in the syntax, and at the same time it must be associated with certain Roots inherently. This aspect of the analysis has clear consequences for the theory of features and their distribution in different modules of the grammar. In addition, it raises serious questions about the claim that Roots are not present in the syntactic derivation. After considering two analyses of the feature in question that are consistent with the idea that Roots are always inserted postsyntactically, and examining their shortcomings, I offer an analysis suggesting that certain Roots may be present in the syntactic derivation to begin with, and I examine the issues surrounding the various treatments of this feature.

After clarifying the status of the feature involved in the Latin perfect, I explore the implications the analysis has for notions of category, and the role of category in syntax and morphology. The analysis I present is one in which category labels for Roots (i.e., for the lexical vocabulary) are dispensed with entirely. The surface morphological differences between "verbs" and "adjectives" reduces to the syntactic structures in which Roots appear, in conjunction with agreement 
processes defined to operate in terms of these structures. The most important role in determining what "category" a Root is realized as is played by the functional heads in the local environment of the Root. These consist of abstract morphosyntactic features and are labeled as D(eterminer), $\mathrm{T}$ (ense), Asp(ect), and so on. The implications of this treatment, and a comparison of the analysis presented here with other models of syntax/morphology interactions, are presented in the concluding sections.

\section{The Latin Perfect}

The basic facts to be investigated are as follows. Latin shows a split in the realization of its perfect tense/aspect forms. ${ }^{6}$ The perfect active is a synthetic form with an aspectual affix and a specific set of endings varying for person/number, as shown in (3). ${ }^{7}$ The perfect passive, on the other hand, is analytic, with a participle agreeing in gender and number, and the verb 'to be' (4). ${ }^{8}$

${ }^{6}$ The same is true of the other parts of the perfect system, that is, the pluperfect and the future perfect.

In terms of its interpretation, the forms called "perfect" in Latin are either perfect or perfective. This is a result of the fact that the Latin perfect represents the collapse of two distinct Indo-European categories, the perfect and the aorist, on both morphological and semantic levels. The ambiguity of the perfect form is noted by later Latin grammarians, for example, Priscian in the 5th century (see Wackernagel 1920, Binnick 1991): "We have the perfect for both the Greek perfect and Greek aorist"' (from Wackernagel 1920:187). Relating the Latin situation to Greek does not clarify the matter entirely, as the Greek aorist is not always interpreted as a "past perfective." Moreover, the interpretation of the Classical Greek perfect is itself somewhat complex; it is elucidated in the study of Wackernagel (1904) (see also Chantraine 1927 and, for a recent compilation/analysis, Sicking and Stork 1996). For a discussion of some of the Latin facts, see Serbat 1980 and other papers in that volume. Theoretically, this behavior in the perfect raises a number of questions about how the features accounting for these two interpretations are distributed in the clause. As I cannot hope to address these here, I will simply use the feature [perf] as an abbreviation for relevant syntacticosemantic features.

One further case is worth noting. In some cases the past participle with 'be' has a stative interpretation, as in the English stative passive The die is cast. In such cases, although the surface form is the same as that found with the passive perfect, the underlying structure is presumably one in which 'be' takes a small clause complement, or in any case a structure that differs from the "normal" clauses studied here.

${ }^{7}$ There are a number of morphological forms associated with the perfect active, stemming, as noted above, from the fact that this category represents the fusion of two distinct categories in Indo-European. The following set of forms from Allen 1931 illustrates some of the variety found in the formation of the perfect:

(i) a. -v-: amō 'love', perf. am-ā-v-1-1

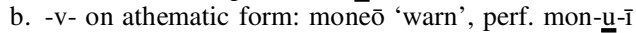

c. -s-: scribō 'write', perf. scrip-s-ī (cf. Greek s-aorist)

d. Reduplication: cadō 'fall', perf. ce-cid-ī (cf. Indo-European perfect)

e. Vowel change: videō 'see', perf. vīd-ī

f. No change: vertō 'turn', perf. vert-1̄

The last three types here have a $\emptyset$-allomorph of the perfect suffix, along with (in some cases) morphophonological readjustment to the stem.

In addition, some of the person/number endings found in the perfect are unique to this category (e.g., the $1 \mathrm{sg}$. and 2 sg.); others contain familiar components in addition to pieces found only in the perfect.

${ }^{8}$ In presenting the endings $-\bar{l}$, -isti, and so on, in the active, I have left an -is- component, found in the 2 sg., 2 pl., and 3pl. (at least historically; it is changed by rhotacism to -er- in the last case), unsegmented; it is occasionally regarded as an independent formant. This is diachronically the same as the -is- found in the pluperfect, discussed in footnote 49. 
(3) Perfect indicative active ${ }^{9}$

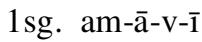

'I have loved'

2sg. am-ā-v-istī

'you have loved'

3sg. am-ā-v-it

'he/she has loved'

1pl. am-ā-v-imus

'we have loved'

2pl. am-ā-v-istis

'you have loved'

3pl. am-ā-v-ērunt

'they have loved'
(4) Perfect indicative passive

1sg. am-ā-t-us/-a/-um sum

'I was/have been loved'

2sg. am-ā-t-us/-a/-um es

'you were/have been loved'

3sg. am-ā-t-us/-a/-um est

'he/she was/has been loved'

1pl. am-ā-t-î/-ae/-a sumus

'we were/have been loved'

2pl. am-ā-t-î--ae/-a estis

'you were/have been loved'

3pl. am-ā-t-1/--ae/-a sunt

'they were/have been loved'

One response to this situation as it is presented in descriptive grammars is to regard it as a matter of classificatory importance only, without a basis in the linguistic system. For instance, one might hold that the analytic passive perfect is not the same as the synthetic perfect in terms of the temporal/aspectual features involved, but is instead something composed of different parts to achieve a similar meaning. Alternatively, the two could be the same in terms of the features involved, but the features would be distributed differently in the hierarchical structure. If either of these approaches were correct, the difference in form would have to be ultimately reducible to a difference between passive and active syntax. In the next section I show that this is not the case. In terms of its morphosyntactic composition (i.e., at the level of features distributed in a syntactic structure), the analytic perfect is just as much a part of the "verbal" system as any synthetic form. ${ }^{10}$ The realization of the Root as a participle follows from properties of Latin morphology.

\section{Syntax and Morphology in the Perfect}

The arguments of this section show that the appearance of analytic versus synthetic forms in the Latin perfect is determined by the presence of a feature [pass], which is (a) systematically correlated with the syntax of passivization, and (b) inherently possessed by certain Roots, for reasons that are not related to passive syntax.

As noted in the preceding section, one assumption might be that active and passive syntax are simply different from each other in the Latin perfect, such that the passive is, by virtue of its

${ }^{9}$ In examples and tables I will represent Latin orthographically.

${ }^{10}$ Traditional analyses of Latin have also taken the position that the analytic perfect is actually part of the verbal system on the same level as the synthetic forms; see, for instance, Brugmann 1895. The reasoning in such cases was based on the fact that the interpretation of 'be' + participle was distinct from that of 'be' and a "simple' adjective; the former had the temporal and aspectual properties noted in footnote 6, whereas the latter was simply present tense. For further discussion of the transition from "deverbal adjective" to "participle" in traditional terms, see Wackernagel 1920: $288 \mathrm{ff}$. 
syntax, necessarily analytic. ${ }^{11}$ Evidence against this view is provided by the perfect forms of certain deponent verbs. Deponent verbs are only capable of appearing in passive form, but may appear in active syntax, as I will show below. ${ }^{12}$

For illustration, compare the present passive forms of $a m \bar{o}$ 'love' (a regular verb) with the present forms of hortor 'to exhort' (a deponent).

(5) Present passive

am-or 'I am loved'

am-ā-ris 'you are loved'

am-ā-tur 'he/she is loved'

am-̄a-mur 'we are loved'

am-ā-min̄̄ 'you are loved'

am-a-ntur 'they are loved'
(6) Present of deponent

hort-or 'I exhort'

hort-ā-ris 'you exhort'

hort-ā-tur 'he/she exhorts'

hort-ā-mur 'we exhort'

hort-ā-min̄̄ 'you exhort'

hort-a-ntur 'they exhort'

In addition to the forms in (5), normal verbs like amō have active forms. For the present indicative, these are as follows; these active forms simply are not found with deponents like hortor:

(7) Present indicative active

am-ō 'I love'

am-ā-s 'you love'

am-a-t 'he/she loves'

am-ā-mus 'we love'

am-ā-tis 'you love'

am-a-nt 'they love'

The identity between deponent verbs and the passives of normal verbs extends to the perfect. Deponent verbs have no synthetic perfect forms, but are instead always analytic in the perfect.

(8) Perfect of a deponent

*hort-ā-v-ī 'I (have) exhorted'; compare (3)

hort-ā-t-us sum 'I (have) exhorted'

The description above covers the basic morphological properties of deponent verbs. I now show that certain deponent verbs — specifically, a certain set of transitives — must be treated as

${ }^{11}$ This possibility has to be stated as specific to the perfect, given that other passives in Latin are synthetic (cf. laud-ō 'I praise', laud-or 'I am praised').

${ }^{12}$ Deponent verbs are covered in detail in all major descriptive grammars and handbooks of Latin. Specific studies that bear on the issues addressed here will be cited as the discussion proceeds. I am referring to the forms of deponents and verbs in passive syntax as "passive"' only for convenience, and in accordance with standard usage for Latin. As I will make clear below, this form is not exclusively associated with passive syntax, but also appears with syntactically related formations.

In addition to the verbs that appear as nonactive in all tenses and moods, there are a few verbs that show different voice forms in different tenses. Verbs that are deponent only in the perfect are referred to as "semideponent" (cf. audeo 'I dare', ausus sum 'I have dared'); other verbs of this type are fideō 'trust', gaudeō 'rejoice', and soleō 'be wont'. Sommer (1914) notes that many of these verbs had synthetic, active perfects in early Latin. 
being inherently specified for a feature responsible for their inflectional properties, which I label [pass]. ${ }^{13}$ Syntactically, some verbs of this type are not different from their active, nondeponent counterparts. ${ }^{14}$ Effectively, then, certain verbs possess this feature for reasons that have nothing to do with passive syntax or related semantics.

If the verbs in question appeared in passive form for systematic syntacticosemantic reasons, they would be expected to form a natural class; but they do not. The conclusion that there is no common syntactic or semantic basis for uniting the deponent verbs is shared by earlier authors; see Draeger 1878:149 and Meillet 1966, along with Baldi 1976 and references found there. This approach, holding that synchronically deponents have their special property somewhat arbitrarily, is contrasted with other traditional treatments of the topic, which seek a lexicosemantic basis for the class. ${ }^{15}$ The lexicosemantic approach also defines more recent typological studies of voice (e.g., Klaiman 1991, Kemmer 1993, 1994, and related work). Before I proceed to the syntactic properties of transitive deponents, I will address points raised by the "semantic" approach to deponent verbs, concentrating on Kemmer's (1993) discussion.

Kemmer's functional/typological account of the "middle voice" (including in this case the Latin "passive") takes middle morphology as a unified semantic concept, expressing the limited differentiation of participants (whether actors or events) in the situation described. Thus, in comparison with normal, active form, the middle (= passive in Latin) forms indicate that actors or events are in some sense undifferentiated. Discussions of this type are difficult to assess in the present context, in that they make no specific claims about how syntax, semantics, and morphology interact with one another; the emphasis is instead on correlating morphological forms with situation types. Without getting into the details of how such a semantic approach to voice fares more generally, the specific point to be made here with respect to Latin is that this type of approach has failed to offer independent reasons for thinking of certain transitive deponents as being syntacticosemantically distinct from regular transitives. To the extent that Kemmer's discussion makes any predictions about the syntax at all, it seems to predict that deponents should be "less transitive" than their nondeponent counterparts. However, no criterion independent of the "middle" morphology itself is put forth as a means of identifying this "middle" semantics. ${ }^{16}$ This is not

${ }^{13}$ It might be the case that there are unergative deponents as well; but I will focus on the transitives here.

${ }^{14}$ Other verbs classified as deponent show passive forms for reasons that are arguably syntactic. For instance, a number of intransitive deponents, such as morior 'die', can be treated as unaccusatives (Embick 1997) and fall into identifiable lexicosemantic classes (cf. Levin and Rappaport-Hovav 1995). I will focus here on the set for which such a syntactic analysis is not possible.

${ }^{15}$ The approach seeking a unified semantics also has a long history, and is closely tied to the question of whether there is a unified semantic basis for the Indo-European middle voice. For a summary of traditional approaches to the latter, see, for example, Gonda 1960a,b. The typical strategy in such treatments is to (a) attempt to identify a Gesamtbedeutung ('unified meaning') for the "middle" and (b) to simply assert that all deponents are somehow connected with this. I will not attempt to review the literature here, but even for Latin alone it is vast; Nölting 1859 already contains a review of much earlier discussion. Baldi (1976) documents the fact that although certain subregularities may be found with deponents, there is no single semantic category that unifies them.

${ }^{16}$ Part of Kemmer's argument for there being a semantic correlate to deponent verbs is typological; she identifies a number of cases in which verbs of the same meaning appear as deponent in unrelated languages. These correlations seem to stem primarily from the fact that a number of the verbs classified as deponent in different languages are unaccusatives or psych predicates, that is, classes in which a certain amount of crosslinguistic semantic similarity obtains; see footnote 14. 
surprising, for as I will now show, there are certain transitive deponents that behave indistinguishably from normal agentive, transitive verbs, beyond possessing [pass] inherently.

The arguments for treating certain deponents as possessing [pass] inherently are as follows. To begin with, in terms of their basic appearance, transitive deponent verbs behave like other (i.e., nondeponent) transitives; that is, they take nominative subjects and accusative objects. ${ }^{17}$

(9) Puer mīlitem sequi-tur. boy-NOM soldier-ACC follow-PASS.3sG

'The boy is following the soldier.'

There is thus no reason to suspect that the syntax here is anything other than that found with normal transitives. Specifically, there is no reason to suppose that these verbs are really "covertly passive," that is, that they involve syntactic operations related to passivization. ${ }^{18}$ There is, moreover, no reason based on lexical semantics to treat certain transitive deponents as anything other than normal transitives. This can be seen here with cōnsector 'hunt down' and aggredior 'attack' (also see (27a)).
a. L. Licinius Crassus cōnsul quōsdam . . cōnsectātus
est
L. Licinius Crassus consul PRON-ACC.INDEF . . . hunt-down-PART be-PRES.3SG
et interfēcit.
and kill-PERF.3sG
'L. Licinius Crassus when consul hunted down and destroyed a certain group ...' (Cic., Dè Inventione II.32.111)

b. Cethegus Cicerōnis iānuam obsidēret eumque
Cethegus Cicero-GEN door-ACC beset-IMPERF-SUBJ-3sG him-ACC = and vī aggrederētur.

violently attack-IMPERF-SUBJ-3SG

'Cethegus was to beset Cicero's door and assault him.'

(Sall., Cat. XLIII.2)

The pattern exhibited above is telling, as it removes one option for the analysis of these verbs. One way of implementing the proposal that deponents really are "passive" in some sense would be to say that all deponents are syntactically distinct from agentive transitive verbs. A plausible option at the outset would be to hold that the deponents are like certain psych verbs, with derived subjects and thus passive morphology. ${ }^{19}$ Verbs of this type would be expected to

${ }^{17}$ A small set of transitive deponents (vescor 'eat', ütor 'use', and a few others) takes ablative objects, at least in Classical Latin; Gildersleeve and Lodge (1895) note that earlier these verbs took the accusative. The question of case with passives and deponents is potentially of interest because it has been claimed that "passives" sometimes have the ability to assign accusative case; see Sobin 1985. I will not address this issue here, but will instead present a series of arguments showing that there is no reason to believe that verbs of the relevant type are actually passive.

${ }^{18}$ See section 5 for a discussion of what syntactic configurations are related to the [pass] feature.

${ }^{19}$ For derived subjects with psych verbs, see analyses along the lines pursued in Belletti and Rizzi 1988 and subsequent work; the idea that "passive"' morphology appears in structures without external arguments is discussed below. 
have the semantics and syntactic behavior of psych verbs crosslinguistically. But this is not the case with verbs like aggredior and consector, which are deponent and do not act like psych verbs. These verbs are as transitive, active, and agentive as possible.

A further fact fits in with this treatment of certain deponents as being normal transitive verbs syntactically. In addition to appearing in transitive syntactic environments, some deponents like hortor may also appear in passive syntax; thus, consider the following example, in which the verb in passive syntax is morphologically identical to the one that appears in active syntax: ${ }^{20}$

(11) Ab amīcīs hortā-rē-tur.

by friends urge-IMPERF.SUBJ-PASS.3SG

'He was urged by friends.' (subjunctive)

(Varro in Prisc., GL II 387,2)

The existence of such verbs provides a strong argument that these verbs are syntactically like other active transitive verbs: that is, they are so transitive that they are capable of being passivized.

Finally, there are agentive nominalizations formed from the relevant deponent verbs: for sequor, sec-ū-tor 'pursuer'; for aggredior, aggres-sor 'attacker, assailant'; and for cōnsector, cōnsectā-trix 'one who pursues or strives after' (fem.) (Glare 1982).

The cases adduced above illustrate clearly the point that passive syntax, and the features underlying it, is distinct from the feature [pass] that results in passive forms. That is, the feature underlying passive forms may be present independently of passive syntax. I conclude from these arguments that the relevant deponent verbs are specified for the feature [pass], which is simply a property of the Root. The exact details of this specification will become clear in section 5 .

To summarize the discussion of deponents to this point: The feature [pass] is in this case simply a property of particular Roots, which, when inherently possessed like this, is systematically unrelated to passive syntax. In this way it has a status similar to that of conjugation features, which are crucial for morphological well-formedness. The difference between the two is that the [pass] feature is sometimes inherently possessed and sometimes systematically correlated with passive syntax (see below).

Recall now that deponents and verbs in passive syntax behave identically for the purposes of inflection and for the purposes of the formation of the perfect. This identity is captured as follows. The [pass] feature that is found in syntactic passives is associated with syntactic configurations in which there is no external argument (see Embick 1997, 1998 for a recent treatment of

${ }^{20}$ Verbs of this type, with only "passive", form but with both passive and active syntax, are referred to as verba commūnia. According to the Latin author Aulus Gellius (2nd century), the Latin grammarians used this term because the verbs in question had one form (the nonactive) that was common to both active and passive interpretations (see Gellius 1927). This classification is also found in extant Latin grammars, which postdate Gellius. The commūnia comprise one of the five voices (genera verb $\bar{l}$, literally something like "verbal genders") recognized in the Latin grammatical tradition. For an overview discussion of the treatment of voice in the writings of Latin grammarians, see Hovdhaugen 1987. For some description of the commünia, see Draeger 1878 and Flobert 1975; they are also noted in passing in most handbooks and descriptive grammars. Finally, McCartney (1926) illustrates several ways in which deponent verbs were connected with "passive meaning," in cases in which passive syntax was not an option. 
voice systems in these terms). ${ }^{21}$ The details of this relationship will be made clear as the discussion proceeds and the status of the feature [pass] is clarified. The point to be stressed is that deponents and verbs in passive syntax are related to the same abstract feature [pass], which results in the realization of passive forms. In spelling out this analysis, I will thus be addressing two facts: first, the fact that deponent verbs have only passive form; and, second, the fact that the form of the perfect with passives and deponents is analytic. As the arguments presented in this section show, analytic perfects can be realized in transitive, active syntax; that is, the analytic/synthetic distinction is based on the feature [pass], not on passive syntax per se. The most direct analysis of this fact is one in which the difference between perfect forms is isolated in a single feature; with the exception of this feature, the analysis must employ essentially identical syntactic structures for both analytic and synthetic forms.

In the following sections I present two distinct ways in which the feature [pass] can be treated. The first treats [pass] as a feature of the morphology only, following the idea that only morphological features can be arbitrarily associated with Roots. After showing that this type of solution is problematic, I present a pair of treatments, in which [pass] is visible in the syntax. Before presenting these specific analyses, however, I will outline some assumptions about basic clause structure in Latin.

\section{Syntactic Structure of the Clause}

In analyzing the structure of the Latin verb, I will assume a clause structure consisting of three functional heads, T(ense), Asp(ect), and $v$, as shown in (12).

(12) Syntactic structure (hierarchical; not linear)

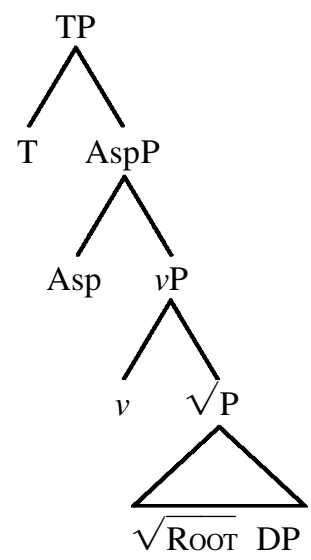

${ }^{21}$ The "passive" inflection is not restricted to syntactic passives, but also appears in anticausatives (intransitives in the causative/inchoative alternation) and certain types of reflexives. This is often referred to as a residual "mediopassive" use of the $-r$ form (from Leumann, Hofmann, and Szantyr 1963:sec. 390).

(i) induō/induor 'put on'

lavō/lavor 'wash'

vehō/vehor 'carry'

vertō/(re-)vertor 'turn' 
The head $v$ here is the light verb that figures in a number of recent syntactic and semantic discussions (see, e.g., Hale and Keyser 1993, Kratzer 1993, Harley 1995, Marantz 1995, 1997, Harley and Noyer 1998, Chomsky 1995, 1998, Lidz 1998, and McGinnis 1998 for some related perspectives). Features here relate to agentivity and causativity, eventivity/stativity, licensing of external arguments, and certain syntactic features such as Case.

The licensing of external arguments is of particular relevance in the Latin voice system; in particular, the systematic appearance of passive forms in Latin is correlated with this feature. ${ }^{22}$ However, this correlation does not work in both directions, as shown clearly in the discussion of transitive deponents above. Thus, the lack of an external argument implies the feature [pass] will be present, but the converse is not true. The exact nature of the correlation between the external argument property and [pass] depends upon whether [pass] is only inserted in the morphology or is present in the syntactic derivation; this will be clarified in the following sections. The point for now is that the conception of $v$ as containing different combinations of features of this type allows for (among other things) a direct treatment of the syntactic conditions correlating with [pass] in Latin. Different feature combinations will be present under $v$, but the ones that have in common the lack of an external argument (i.e., passives and unaccusatives) will be identical morphologically. Passives will have an agentive $v$, along with no external argument, whereas unaccusatives will have a nonagentive $v$ along with no external argument. The common property of lacking an external argument, which correlates with [pass], accounts for the identity in form.

Asp contains features relating to perfectivity and imperfectivity: the completeness or incompleteness of the eventuality associated with the verb and $v$. T contains temporal features such as [past]. Finally, the notation $\sqrt{ }$ here is for the Root, that is, the member of the open-class vocabulary appearing in this position. The reasons for representing the Root with this neutral (e.g., categoryfree) notation will become clear as the discussion proceeds. ${ }^{23}$

The separate status of the heads $\mathrm{T}$ and Asp is most clearly seen in the pluperfect, as in the following form:

(13) amāveram

am- -ā- -v- -er- -am

love Th Asp T Agr

'I had loved ...'

The assumption is that in the default case there will be movement up to $\mathrm{T}$; this results in the pattern of synthetic verb forms seen in tenses other than the perfect. Following movement of

The view that the $-r$ forms figure in a number of systematic alternations apart from passivization is also presented in Baldi 1976.

${ }^{22}$ There are most likely some unaccusatives in Latin that appear in active form; this is never the case with passives, however. Although the reasons behind this "split behavior" of unaccusatives are of interest from the perspective of argument structure, they cannot be addressed here.

${ }^{23}$ One further position is the Th(eme). The theme vowel of the Latin verb is, I assume, the instantiation of a position added in the morphology, onto which conjugation class features of the Root are copied. In the tree it appears as $T h$ on the $\sqrt{ }-v$ unit. For a recent approach to theme vowels in the Distributed Morphology framework, see Oltra 1999. 
the Root to $v$ and Asp to T, I assume that an Agr(eement) node is added in the morphological component, to produce the object shown in (14). ${ }^{24}$

(14) The Latin verb

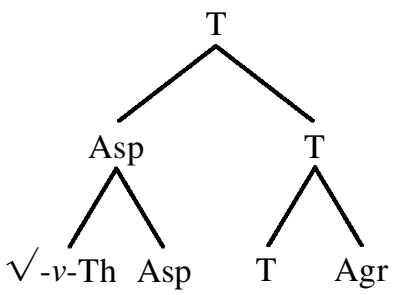

As illustration of two synthetic forms that are realized in this structure, consider the active and passive imperfect of the verb laudo 'praise'.

(15) a. laud-ā-ba-t 'he/she was praising/praised ...'

b. laud-ā-bā-tur 'he/she was being praised'

These two forms will be realized in the structure shown in (16), as will the imperfect forms of deponent verbs (e.g., hortor, imperf. hort- $\bar{a}-b \bar{a}-t u r)$.

(16) Structure/Features

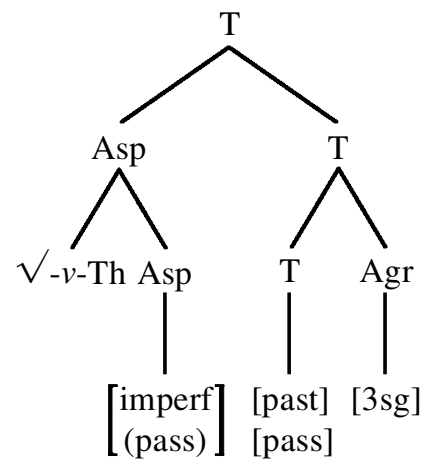

The two cases will be for the most part identical in feature content, differing in whether or not the feature [pass] is present in Asp (see below for the location of [pass]). In this structure the Root position $\sqrt{ }$ will be instantiated by laud-, and the theme position, occupied by the conjugation class feature I, by the theme vowel $-\bar{a}-$. On the assumption that the imperfect aspectual

${ }^{24}$ The analysis is incompatible with one in which separate projections appear for agreement morphemes, as in Pollock 1989. If agreement were located syntactically in agreement projections (AgrP), the analytic and synthetic perfects would have to be associated with distinct syntactic structures; the former with two AgrPs, the latter with only one. For discussion of issues surrounding AgrP, see Iatridou 1990 and Chomsky 1995. 
feature is realized as zero, the tense feature, common to both forms, will relate to the following vocabulary item:

(17) $-b \bar{a}-\leftrightarrow[$ past]

The Agr node will then be realized as follows:

(18) $-t \leftrightarrow 3 \mathrm{sg}$

The result in this case is active laud- $\bar{a}-\not \emptyset-b a-t$.

The realization of synthetic passive forms is more complicated. The reason for this is that whereas the feature [pass], which is directly related to the passive forms, appears in the $\sqrt{ }-v$ domain, or possibly with Asp, [pass] is realized in the T-Agr area, typically in an - $r$ - component. The imperfect is used to illustrate here. ${ }^{25}$

(19) Imperfect passive

laud-ā-ba-r 'I praise'

laud-ā-bā-ris/(-re) 'you praise'

laud-ā-bā-tur 'he/she praises'

laud-ā-bā-mur 'we praise'

laud-ā-bā-min̄̄ 'you praise'

laud-ā-ba-ntur 'they praise'

One option that is available is to treat the passive endings as indivisible units, which are specified contextually to instantiate agreement features when [pass] is present on Asp.

(20) Provisional realization of passive Agr

$$
\begin{aligned}
& \text { 1sg. } \leftrightarrow-(\mathrm{o}) \mathrm{r} / \text { [pass] }_{\text {[pass] }} \\
& 2 \mathrm{sg} . \leftrightarrow-\text { ris } / \longleftarrow \text { [pass] }
\end{aligned}
$$

There is a weakness to this approach, however; it fails to account for the fact that the majority of the passive endings include components that are found in active Agr as well (common components are boldfaced in the passive Agr).

(21) Passive and active

1sg. passive -(o)r; cf. active $-\bar{o}$

2sg. passive -ris; cf. active $-s$

$3 \mathrm{sg}$. passive -tur; cf. active $-t$

1pl. passive -mur; cf. active -mus

2pl. passive -minī; no active counterpart

3 pl. passive -ntur; cf. active $-n t$

25 The form - re of $2 \mathrm{sg}$. was prevalent in earlier Latin; the form - ris is in fact regarded as the original -re, combined with the $-s$ from the active 2 sg. (Sihler 1995:475). 
The danger is thus that the treatment sketched in (20) misses a generalization about components common to the two types of Agr.

A detailed analysis of this issue is presented in Embick and Halle 1999; here I will simply outline the basics of an analysis that segments the passive forms. The essential component to an alternative analysis involves treating $-r$ - as the basic realization of the feature [pass].

The location of the feature [pass] depends upon the analyses of this feature to be presented in subsequent sections. For now, the point is that if the only starting positions for the [pass] feature are below T-Agr, the structure must be readjusted to place [pass] in T-Agr. On this scenario, in order to account for the position of [pass] in the verb (i.e., adjacent (left or right) to Agr) two mechanical operations are required: first, the [pass] feature must be separated from Asp through the process of Fission; and, second, it must be adjoined to Agr, via a form of Morphological Merger (see below). ${ }^{26}$ The modified structure, following the relevant operations, is shown in (22).

(22) Structure after operations

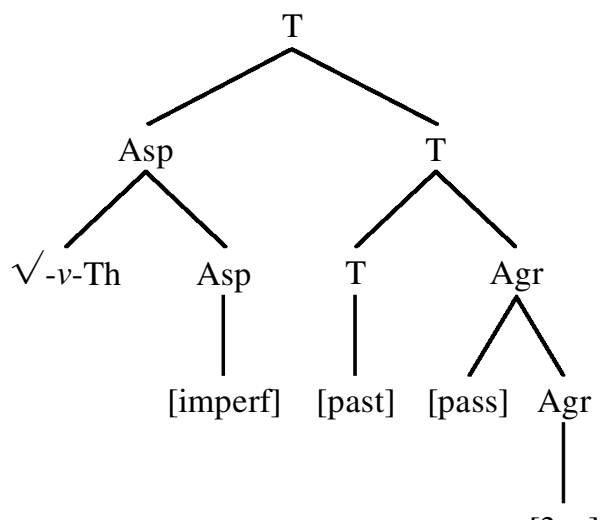

$[3 \mathrm{sg}]$

This provides a position in which the $-r$ of the passive can realize the feature [pass] directly. In order to account for the fact that the $-r$ component follows Agr in 1sg., 1pl., 3sg., and 3pl., while preceding it in $2 \mathrm{sg}$., we can appeal to the fact that the structure in (22) is hierarchical, and linearized as Agr-pass in the default case, but as pass-Agr when 2sg. is present.

A fuller treatment of the Latin conjugation would be required in order to determine the adequacy of the analysis of [pass] in finite forms sketched above. For the time being, however, the point is that there are mechanical derivations that will account for the position of [pass]. In the following sections I present three analyses of a different aspect of the feature [pass], addressing the question of whether it is present only in the morphology, or in the syntactic derivation as well.

${ }^{26}$ The positioning of [pass] in the T complex is problematic; the clearest arguments show that [pass] is low in the structure (i.e., with $v$ or the Root), yet its morphological realization is with T-Agr. The suggestion here merely highlights the problem, which may be resolved mechanically. In part the issues are related to the status of [pass] in the first place, which, as will become clear in section 5 , is complicated. 


\section{The Status of [Pass]}

The status of the feature [pass] in the grammar is the central concern of this section and the next. Earlier sections have established two primary points. First, the feature [pass] underlies the difference between analytic and synthetic perfects. Second, this feature is not exclusively associated with passive syntax; it is also associated with deponent verbs, for reasons that are completely arbitrary.

The discussion now turns to three possible treatments of [pass], each of which has distinct merits and problems. The first solution presented is morphological, claiming that the feature [pass] arises only in the postsyntactic morphology. This solution maintains the idea that arbitrary features of Roots cannot affect the syntax. However, I show it to be problematic on the basis of an argument showing that [pass] is truly active in a syntactic operation. I then present a second solution, based on the idea that [pass] is an uninterpretable syntactic feature. Although this treatment is able to capture the behavior of [pass] and the differences in the Latin perfect, it does so at the cost of a complication in the syntax. I therefore consider a further option, in which the [pass] feature of deponent Roots is visible from the outset of the syntactic derivation, by virtue of the Root's being inserted early.

\subsection{Analysis 1: [Pass] as a Morphological Feature}

5.1.1 Basics of a Morphological Treatment The point of proposing a morphological treatment of [pass] is that it would maintain the claim that Roots cannot be inherently specified for features that are relevant to the syntax. That is, because the formation of an analytic or synthetic form is based on a feature that is sometimes an idiosyncratic property of certain vocabulary items, namely, the inherent specification for [pass] with deponents, the formation of the analytic and synthetic perfects occurs in the morphology. In the syntax the two would be identical, with movement of the $\sqrt{ }-v$ complex to Asp (hierarchical structure is represented in (23) only).

The idea is that the factors conditioning the difference between perfects are not exclusively syntactic in nature. The information required to determine analytic or synthetic form is not available with deponents until after Vocabulary Insertion and does not correlate directly with active or passive syntax. Both have the structure in (23) when coming out of the syntactic derivation; postsyntactic operations, presented in the next section, account for the differences.

5.1.2 Analytic/Synthetic in Morphology In the creation of the synthetic perfect from the structure in (23), a postsyntactic process is required to bring together the T-Agr and $\sqrt{ }-v$-Asp complexes. This is the process of Merger (Marantz 1984, 1988; also Bobaljik 1994, 1995, Embick and Noyer 1999). Unlike syntactic movement, which, although local, can operate over large structures, Merger is defined to operate under adjacency. Used in this sense, adjacency can be stated in terms of hierarchical structure, such that a head can merge with the head of its complement, ${ }^{27}$

${ }^{27}$ The lowering of $\mathrm{T}$ to the verb in English (i.e., affix hopping) is an example of Merger of this type. 
(23) Passive (output of the syntax)

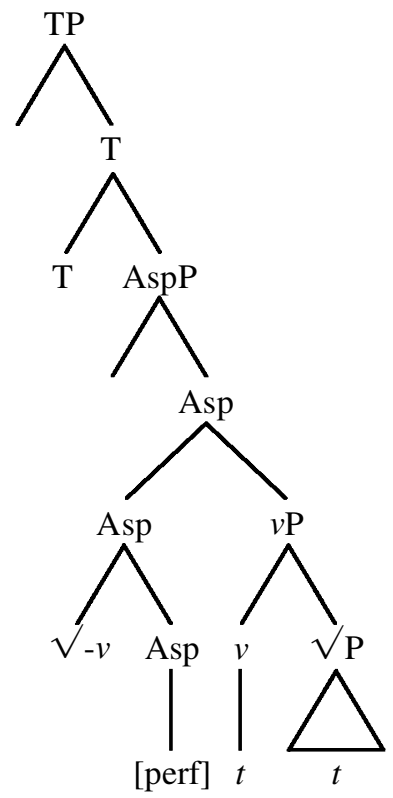

(24) Merger
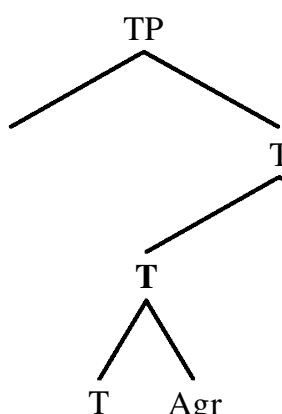

$\mathrm{T}$

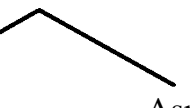

A Agr
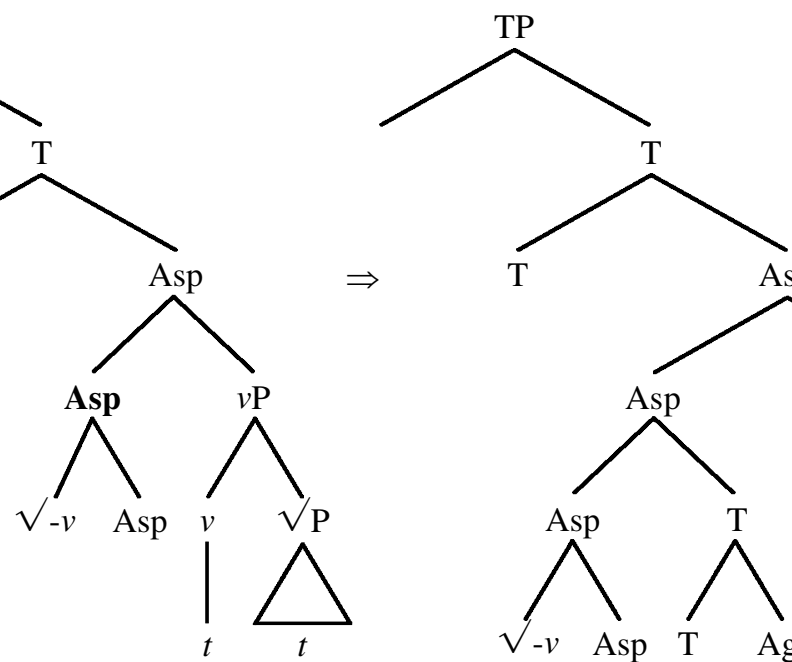

$\Rightarrow$

$\mathrm{T}$

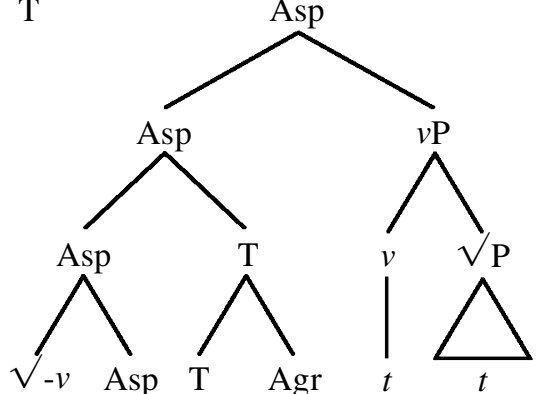

or, adjacency can be defined linearly, such that Merger can put together linearly adjacent elements. In Latin it is the first notion that is relevant. The basic idea behind Merger of this type is that the hierarchical relationship between the T-Agr and $\sqrt{ }-v$-Asp complexes is collapsed; it operates as shown in (24) for the Latin perfect (nodes in question are boldfaced). 
The operation thus has the effect of reducing the T-Agr complex and the $\sqrt{ }$ - $v$-Asp complex, which it dominated syntactically, into a derived structure [[ $\sqrt{ }-v$-Asp][T-Agr] $]$. Notice that aspects of the movements that have taken place are specific to the perfect; namely, in the perfect, syntactic movement creates $\sqrt{ }-v$-Asp, but does not move this further to T. In other tenses the entire complex will be moved to $\mathrm{T}$ in the syntax.

The relationship between this process and the hypothesized feature [pass] is that Merger is precluded from applying in the presence of the morphological feature [pass], whatever its provenance.

(25) Merger in (24) is blocked by a [pass] morphological feature.

This makes concrete the fact that synthetic perfects cannot be formed in the presence of a [pass] feature - it is not simply something about passive syntax that defines the appearance of this form. There are two cases in which Merger may be bled: (a) in the syntactic configurations associated with the [pass] feature, and (b) in the presence of deponents, which bear [pass] inherently. In order to maintain the identity of the feature, in (e.g.) syntactic passives, the feature [pass] would be inserted in the morphological component (see footnote 34 ).

5.1.3 Location of the Pieces In the analysis above, the interaction between $\mathrm{T}$ and Asp (based on whether [perf] and [pass] cooccur) that results in the form of the perfect occurs in a very local domain. However, in terms of the surface word order of analytic perfects, the participle and auxiliary need not appear adjacent to each other in the surface string (participle and auxiliary italicized).

(26) Passives

a. Ea adhibi-t-a doctrīna est...

such-FEM add-to-PART-FEM instruction-NOM be-PRES.3sG

'Such instruction has been given ...'

(Q., Fr.i.1.7; Allen and Greenough 1931:304)

b. Ut ex unō quondam in duōs populōs $d \bar{l} v \bar{l}-s-a$ Albana rēs as out-of one once into two peoples divide-PART-FEM Alban nation est ...

be-PRES.3SG

'As formerly from one people the Alban nation was divided into two ...' (L., I.28.7)

(27) Deponents ${ }^{28}$

a. Lex Terentilia ... novōs adgres-s-a

law-NOM Terentilian ... new-ACC.MASC.PL menace-PART-FEM

cōnsulēs est.

cōnsul-PL.ACC be-PRES.3sG

'The Terentilian law ... menaced the new consuls.'

(L., III.X.5)

${ }^{28}$ The participle adgressa here is an orthographic variant of aggressa, from aggredior 'attack'. 
b. ... quam sī mihī tum essent omnēs grātulā- $t-\bar{t}$.

... than if me-DAT then be-IMPERF.SUBJ.3PL everyone congratulate-PART-PL

'. . . than if everyone had then congratulated me.'

(Cic., Plan. 66)

This is of interest because the process moving the two parts of the perfect is apparently syntactic, in that it moves elements over large structures. At the same time it must follow the determination of a synthetic or analytic perfect. The reasoning is as follows. The assumption we are making is that the determination of an analytic or synthetic perfect only comes about in the morphology (i.e., after the syntax). In order for this to work properly, T must immediately dominate Asp for these heads to be combined by Morphological Merger, the process that creates synthetic perfects. However, the examples above show that $\mathrm{T}$ and Asp can be moved apart from one another.

If all movement happens in the syntax, then the movement responsible for the examples above could potentially move Asp away from $\mathrm{T}$ in cases in which a synthetic perfect should be created. The result would be an active, analytic perfect for a normal verb. ${ }^{29}$

(28) *Laudātus $\quad(\mathrm{X})(\mathrm{Y})$ mīlitem est.
praised-PART (X) (Y) soldier-ACC be-PREs.3sG
'He $(\mathrm{X})(\mathrm{Y})$ praised the soldier.'

But forms of this type do not appear. The conclusion is thus that the optional movements resulting in examples like (26)-(27) must take place after the type of perfect has been determined (i.e., after the morphology).

One interpretation of this fact would be that there is a type of constituent movement that applies postmorphologically (i.e., applies to grammatical structures after Vocabulary Insertion has taken place). The status of such a position is difficult to assess in the abstract. In general, the status of optional movements of any type is somewhat unclear in current syntactic frameworks. ${ }^{30}$ Allowing this postmorphological movement would result in a theory in which there are effectively two syntactic components: first, the pure syntax, operating premorphologically; and, second, a form of syntax that applies after Vocabulary Insertion and effects stylistic movements. In the absence of strong arguments, this is problematic. The surface position of elements may potentially say very little about the syntax, given that their placement could have been brought about in the phonology (i.e., after the syntax and certain morphological operations). Unless the postmorphological syntax could be shown to have properties that differ clearly from those of the premorphological syntax, its existence is questionable. ${ }^{31}$ This point is clear with reference to the process of Merger discussed above. The theory does allow for this postsyntactic process to effect movementlike operations. However, Merger is unlike syntactic movement in being defined to apply under adja-

\footnotetext{
${ }^{29}$ This assumes that the morphology does not filter-that is, that it interprets syntactic structures only and does not render some syntactic structures ungrammatical.

${ }^{30}$ For instance, Chomsky (1998:21) hypothesizes that stylistic movements might occur late on the PF branch.

${ }^{31}$ It should be noted, however, that PF movements performing syntaxlike operations have been proposed in other contexts; see, for instance, Sauerland, to appear, and Elbourne 1999.
} 
cency, under limited conditions-primarily repairing morphological or phonological problems (e.g., satisfying clitic or affix dependencies). It is thus clearly not a second syntax in the sense that the process required to generate examples like (26)-(27) would be.

The position I will take is that the movements found in (26)-(27), which look like syntactic movement, are in fact the result of a single syntactic computation, which occurs prior to morphology. That is, there is no postmorphological second syntax. Part of the justification for this stance is the idea that the existence of a PF movement of the type discussed above must be proven, not assumed. ${ }^{32}$ The consequence of this position for the status of [pass] is clear: because the existence of such movement follows from the morphological treatment of [pass] developed in this section, we have an argument that this solution should be abandoned in favor of a syntactic status for [pass].

\subsection{Analysis 2: [Pass] in the Syntax}

The following points must play a role in a syntactic treatment of the feature [pass]. First, as noted already, the feature [pass], which is responsible for passive morphology and the form of the perfect, does not directly bring about passive syntax whenever it is present; the argument based on deponents makes this clear. Furthermore, there is no basis for interpreting the feature [pass] in all of its occurrences, as this would require deponents and true syntactic passives to have some common interpretive quality, contrary to what was demonstrated above.

Given these criteria, one possibility is to treat [pass] as an uninterpretable syntactic feature and to make the syntactic difference between the perfects result from this. In outline, the analysis of [pass] as an uninterpretable feature in the syntax captures the behavior of the perfect by preventing movement of [perf] Asp to T. ${ }^{33}$

(29) [Perf]Asp does not move to T when [pass] is present.

The structures in (30) and (31) are then relevant for the two perfects.

In cases in which the syntax is "passive" (i.e., in which there is no external argument), the appearance of the feature [pass] can be tied to the features of $v$. That is, just as there is a $v$ related to active, transitive syntax, and with a particular feature content, so there is a $v$ associated with structures in which only internal arguments are licensed. The idea is then that the feature [pass] is present below $v$ when $v$ does not license an external argument syntactically. ${ }^{34}$ Other properties

32 Thus, if it becomes clear that such movements are necessary, the morphological treatment of [pass] outlined in section 5.1.2 will become an option. In order to prevent the derivation of analytic perfects for regular verbs in active syntax, however, something additional is required.

${ }^{33}$ The account of Giorgi and Pianesi $(1991,1997)$ takes the analytic/synthetic difference to follow from the categorial status of their projection T2 (basically Asp here) in combination with properties of passive syntax. As shown in section 3 , this treatment is unworkable; analytic or synthetic form has nothing to do with passive syntax per se. In a sense, however, Giorgi and Pianesi seek to derive the surface category from the position to which movement has occurred in the tree; to this extent, their account is similar to that presented here.

${ }^{34}$ As opposed to systems in which voice features are assigned postsyntactically, in a syntactic configuration with no external argument; see Embick 1997, 1998 for discussion of such operations, and for discussion of the syntactic and semantic features of $v$ found with passives. For recent perspectives on the syntax associated with this type of $v$, see also Lidz 1998 and McGinnis 1998. 
(30) Synthetic
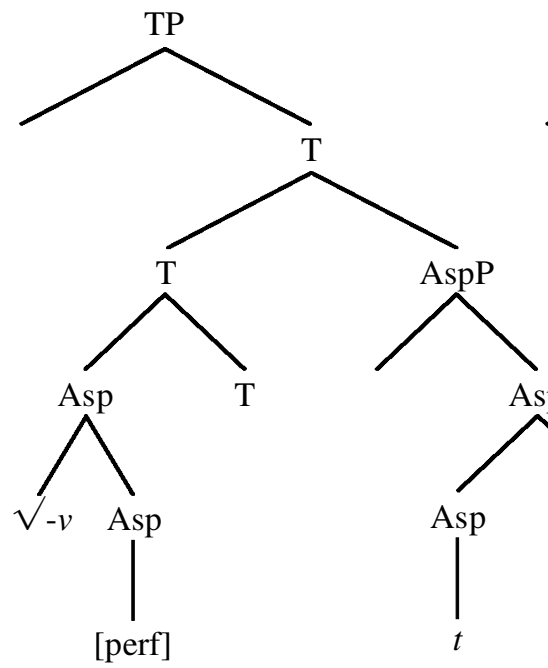

(31) Analytic
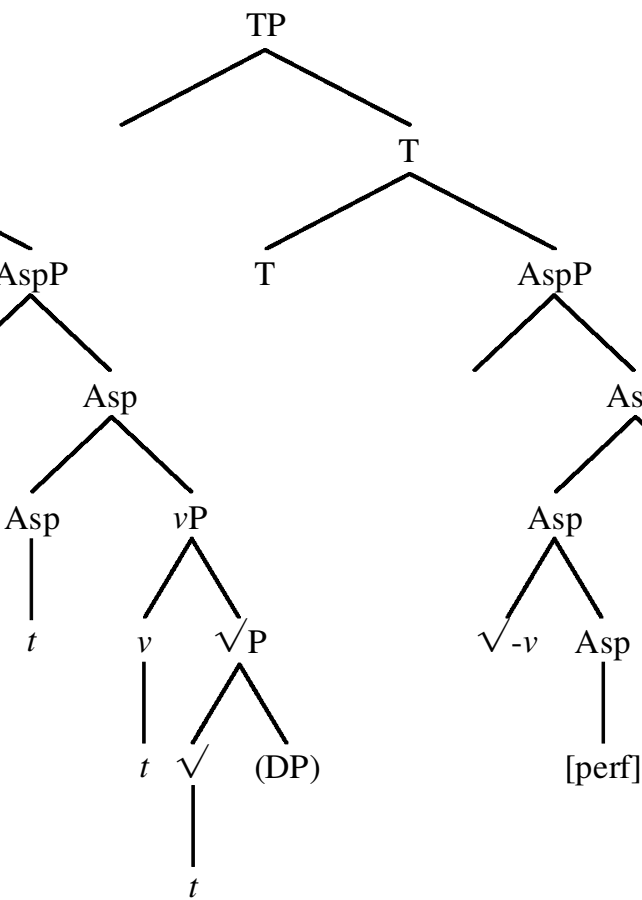
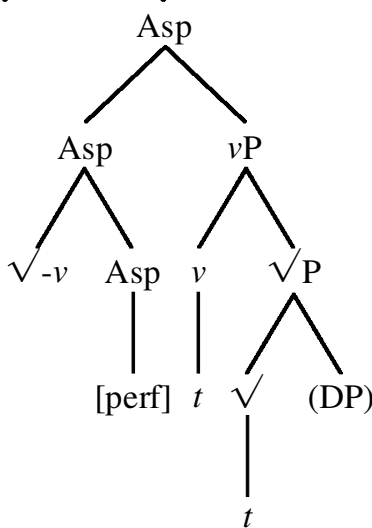

of $v$, relating to agentivity for instance, will determine whether the resulting structure is passive or unaccusative.

With deponent verbs, the feature [pass] is required for the insertion of the relevant Roots. This can be captured by assuming that a [pass] feature is generated syntactically in the position of the head of the complement of $v$ (i.e., the position into which Roots are inserted). Effectively, the deponents are licensed for insertion only into Root nodes containing the feature [pass] (see Harley and Noyer 1998 for discussion of the licensing of Roots).

(32) Deponent $\leftrightarrow \sqrt{ }$ [pass]

Because of this condition, deponents will not be inserted into "normal" Root positions; they will appear only when [pass] has been generated on that position. In addition, the feature [pass] below $\sqrt{ }$ is not associated with any syntactic effect; the $v$ above may be transitive and active, as it in fact is with transitive deponents.

In addition to the above points, there is the question of the location of the feature that the $\sqrt{ }-v$ [pass] features will be checked against. That is, the uninterpretable [pass] feature in the $V_{-v}$ domain must be checked by a higher category that attracts [pass] in order for the derivation to be legitimate. For concreteness, I will assume that it is T that attracts [pass] in tensed clauses; otherwise, Asp (nontensed contexts). Although not a great deal hinges on this choice, the realization of passive morphological forms in Latin is associated with the T-Agr position, suggesting a 
connection between $T$ and [pass] that can be captured by specifying a featural relationship between the two.

The effect that the [pass] features have on syntax is simple. When [pass] and [perf] are both present, movement to $\mathrm{T}$ from Asp is impossible. Thus, $V_{-v}$ remain in Asp. As a result, there is an analytic form in the perfect whenever [pass] is present. The actual derivation of forms in this structure will be undertaken in the next section. For now, there is the question of how combinations of [pass] features in the syntax are checked. Given the proposals above, there are three positions that figure in derivations with [pass]:

(33) a. T (attracts/does not attract [pass])

b. Under $v$, associated with the lack of an external argument

c. Under $\sqrt{ }$, the position of the Root (i.e., the position where the insertion of deponents is licensed)

The two types of $\mathrm{T}$ here have to do with the realization of passive forms on T-Agr; that is, the $\mathrm{T}$ that attracts [pass] results in what is effectively passive agreement. The overt manifestation of this is in the realization of the - $r$-form passive agreement suffixes noted earlier. Within the verb, these appear in the T-Agr complex; and this follows naturally if T attracts [pass] in certain cases. The "'agreement' -type features relating to [pass] on T are then expressed on T-Agr. Syntactically, this type of $\mathrm{T}$ has to be accompanied by a [pass] feature in the $V-v$ domain. ${ }^{35}$

It is important to emphasize that only the [pass] generated on $v$ is directly related to the syntax of passivization. The other sites in which the [pass] feature can be generated are not specifically correlated with the lack of an external argument.

In terms of their interactions (i.e., in terms of what happens in derivations in which [pass] appears in different combinations of these positions), there are the cases in (34) to consider. ${ }^{36}$

(34) Derivations with [pass]

\begin{tabular}{llll} 
Name & T property & $v$ property & Root property \\
\hline Case 1 & T does not attract [pass] & no [pass] under $v$ & no [pass] under $V$ \\
Case 2 & $\mathrm{T}$ does not attract [pass] & no [pass] under $v$ & [pass] under $V$ \\
Case 3 & $\mathrm{T}$ does not attract [pass] & [pass] under $v$ & no [pass] under $V$ \\
Case 4 & $\mathrm{~T}$ does not attract [pass] & [pass] under $v$ & [pass] under $V$ \\
Case 5 & $\mathrm{T}$ attracts [pass] & no [pass] under $v$ & no [pass] under $V$ \\
Case 6 & $\mathrm{T}$ attracts [pass] & no [pass] under $v$ & [pass] under $V$ \\
Case 7 & $\mathrm{~T}$ attracts [pass] & [pass] under $v$ & no [pass] under $V$ \\
Case 8 & $\mathrm{~T}$ attracts [pass] & [pass] under $v$ & [pass] under $V$ \\
\hline
\end{tabular}

${ }^{35}$ When movement to $\mathrm{T}$ is blocked in the [pass] perfect, this requirement of $\mathrm{T}$ would be met by virtue of the relationship Agree, in the sense of Chomsky 1998, that is, without movement of the [pass] feature to T in the syntax. All other things being equal, this would predict that passive forms appear with esse, contrary to what is actually found. Thus, something additional is needed here if this approach to [pass] is to be maintained.

${ }^{36}$ The verba commūnia, the verbs noted above as having only passive form but either passive or active syntax, require an additional assumption. In these cases there would presumably be a [pass] feature on the Root position, as well as one on $v$ in cases of passive syntax. Mechanically, the simplest treatment in this case would be one in which the two 
The results of each of these derivations, along with the verb types they correspond to, are as follows:

Case 1: Normal syntax, in which deponent verbs will not appear.

Case 2: Deponent verb licensed in Root position; the uninterpretable feature goes unchecked, and the derivation crashes. Prevents deponent verbs from appearing in syntax without T[pass]. Case 3: Syntax with no external argument, but in which the [pass] feature is unchecked and the derivation crashes.

Case 4: Passive syntax in which only deponent verbs are inserted; the [pass] feature is not checked, on the assumption that [pass] on $v$ and [pass] on the Root do not interact; see case 8 .

Case 5: Passive forms with neither passive syntax nor a deponent verb. The requirement of $\mathrm{T}$ is not met, and the derivation crashes.

Case 6: The derivation for deponent verbs; these are licensed in the Root position, and the [pass] feature is checked by $\mathrm{T}$.

Case 7: Passive syntax with normal verbs; the [pass] feature on $v$ is checked against $\mathrm{T}$. Case 8: Assuming that the [pass] features on $v$ and $V$ do not interact with one another, this is the case of verbs with only passive forms appearing in passive syntax (the verba communia discussed earlier).

Mechanically, this solution provides a means of treating [pass] as a syntactic feature, while maintaining the idea that it is associated with certain Roots inherently. In addition, by treating [pass] as an uninterpretable syntactic feature, the solution maintains Feature Disjointness. This treatment incurs a cost, however. The syntax is complicated by the workings of the feature [pass] in (34). ${ }^{37}$ And the syntactic effect that motivated a syntactic treatment of the feature [pass] in the

[pass] features of $\sqrt{ }-v$ are effectively treated as one for the purposes of checking with the [pass] on Asp. Something like this must be stipulated in any case, to prevent a derivation in which a [pass] feature on the Root position licenses a deponent and is checked against a [pass] on $v$.

The account presented here has three possible positions for [pass]; restricting the positions in which the feature may be generated has other consequences. For instance, one alternative would involve restricting the lower [pass] feature to $v$. This would simplify part of the system, in that there would only be one lower locus for the [pass] feature; deponents might then be specified as follows:

(i) Deponent $\leftrightarrow \sqrt{ } /$ [pass]

However, this treatment raises serious questions about the nature of competition for Roots. All other things being equal, the specification in (36) would predict that deponents should always win out over normal verbs for insertion when [pass] is present. This predicts that normal verbs would have no passive forms, which is clearly incorrect. The possibility exists that competition for Roots simply behaves differently from the competition found with functional morphemes. This position has clear ramifications for other aspects of the theory, in the treatment of suppletion, for instance (see section 5.3). But the scope of the issues raised by this stance take it beyond the concerns of this article.

Another problem for this type of treatment concerns the status of [pass] on $v$. In the analysis presented in the preceding section, [pass] on $v$ is always correlated with a syntactic effect-the failure to license an external argument. On the treatment just outlined, this is no longer the case. Among other things, the question of how to prevent normal verbs from being inserted into "deponent syntax" is unresolved.

${ }^{37}$ The treatment of [pass] as an uninterpretable feature also makes certain predictions, the status of which is not clear. For instance, it seems to predict that deponent Roots will not appear in "simple" nominalizations, that is, nominalizations without an Asp head. The reason for this would be that the [pass] feature required for the insertion of the deponent would not be checked, if there were no higher head. 
first place — namely, the nonmovement of [pass][perf] Asp to T-is captured orthogonally. That is, the restriction to the effect that movement of [pass][perf] Asp to $\mathrm{T}$ does not occur requires only that [pass] be visible in the syntax. The further claim, that [pass] is an uninterpretable feature, arises only as a result of treating Roots as subject to Late Insertion; because features of the Root itself cannot be visible, an uninterpretable feature is the only remaining candidate to associate with the effect to be captured. With the hypothesis that Roots are not visible in the syntax, this was the only option for making [pass] syntactically active. In the following section I present a second syntactic option: the treatment of [pass] as a feature visible in the syntax, with specific Roots visible in the syntax as well.

\subsection{Analysis 3: A Syntactic Treatment with Roots in the Syntax}

The treatment offered above is based on the argument that [pass] has syntactic effects. As noted, the analysis according to which [pass] is an uninterpretable feature is only one possibility; moreover, it has shortcomings, in the sense that it complicates the syntax somewhat. A second idea, one that avoids the complications of checking this feature, would be to hold that the feature [pass] is actually interpreted when it appears on $v$, but not interpreted when it appears arbitrarily with deponents. The result of this interpretation would unify passives and unaccusatives, whose common component is the lack of an external argument. ${ }^{38}$ On this approach, deponent Roots bring the feature [pass] into the syntactic derivation, by virtue of being visible in the syntax; that is, under this option (at least deponent) Roots are inserted early. ${ }^{39}$

$$
\begin{aligned}
& \text { Representation of a deponent (provisional) } \\
& \sqrt{ } \text { Rоот[pass] }
\end{aligned}
$$

Recall that [pass] has a dual nature; it is required when no external argument is present, but the converse is not true. Transitive deponents appear with external arguments. This behavior can be accounted for as follows. When [pass] is generated on $v$, it affects Merge: no external argument is merged with $v$ when [pass] is on $v$. However, the complement of $v$-namely, the Root and its argument-will contain [pass] if the Root is deponent. From the perspective of $v$, the [pass] feature in its complement has no effect on its syntactic possibilities; a $v$ can have an external argument even when [pass] appears with the Root. Thus, there is no contradiction with transitive deponents. Subsequently in the derivation, however, the $V_{-v}$ complex will contain the feature

${ }^{38}$ Of course, this regards this property uniting passives and unaccusatives as having real semantic content; and this is contentious. The point is that by treating the feature in this way, there is no need for checking, in contrast with the previous syntactic analysis. Ultimately the status of this assumption will depend upon an understanding of the nature of the "no external argument" property that [pass] encodes.

${ }^{39}$ The realization of the functional vocabulary would still be postsyntactic; in certain key respects the resulting picture would be similar to the model presented in Halle 1990. Furthermore, the argument here is only that the features of certain (not all) Roots need to be visible in the syntax.

It might also be possible to treat the insertion at the phase level (Chomsky 1998), with Vocabulary Insertion taking place on these structures derived in a cyclic computation. Whether or not this would make predictions different from a theory in which Roots are present in the syntax from the outset is unclear. In either case the point is that the Root bears a syntactically relevant feature. 
[pass], following movement of the Root to $v$. From the perspective of subsequent syntactic operations, [pass] in the $V_{-v}$ domain will have an identical effect, whether it originates on $v$ or with the Root. Specifically, movement of Asp to T will be blocked in each case. This is effectively all that must be said about [pass], at least as far as the syntax is concerned. No additional mechanisms or assumptions are required to account for the checking of [pass].

I will compare the two syntactic treatments of [pass] below. First, however, I turn to a further positive consequence common to both syntactic treatments of this feature, which suggests that a syntactic solution is justified.

\subsection{A Consequence: Active Perfect Participles}

A syntactic treatment of [pass] allows for an asymmetry in the Latin participial system, manifested in environments without $\mathrm{T}$, to be accounted for directly. The basic fact is that whereas normal verbs simply lack active perfect participles altogether, deponent verbs do have perfect participles that appear in active syntax. The relevant environment is called the ablative absolute, in which the participle appears with ablative case. The following example, taken from Brugmann 1895: 137 , illustrates this with the deponent verb polliceor 'promise': ${ }^{40}$

$$
\begin{aligned}
& \text { (36) } \ldots \text { Sullā omnia pollicitō ... } \\
& \ldots \text { Sulla-ABL everything-NEUT.ACC promise-PART.ABL.SG.MASC } \\
& \text { 'Sulla having promised everything . . ' } \\
& \text { (Sall., Jug. CIII,7) }
\end{aligned}
$$

Syntactically, Latin simply does not allow the combination of active syntax and perfect aspect in participles. The restriction here is to participles, and not simply nonfinite forms; infinitives, for instance, allow perfect active syntax (cf. amō 'love'; amāvisse/amāsse 'to have loved'). Whatever the reason for this effect in participles, the statement of the restriction is something like the following, which is simply a property of Latin syntax. ${ }^{41}$

(37) Asp [perf] not selected by T selects [pass].

That is, it requires [pass] in its complement. Recall now that [pass] can be present for one of two reasons: it can be either assigned syntactically or associated inherently with deponent verbs.

On the first syntactic solution, with regular verbs in active participial syntax, if [pass] is present with [perf], there will be no corresponding [pass] feature on $v$. Thus, the feature [pass] on Asp will be unchecked, and the derivation will crash. With the special Root-licensing [pass]

\footnotetext{
${ }^{40}$ Example (36) shows an object bearing the case normally assigned by the participle, here accusative. The active past participle appears in this type of syntax (with the normal object case) only in Sallust and after (see Brugmann 1895).

The importance of active perfect participles of this type was pointed out by Andrew Carstairs-McCarthy in a communication to Rolf Noyer, and I gratefully acknowledge this lead.

${ }^{41}$ The statement of this restriction operates on the assumption that $\mathrm{T}$ is not present in such structures. The restriction itself is not meant to express a filter of some type, or anything beyond a statement of the facts, presumably reducible to something else. Exploring the nature of restrictions of this type is, of course, an interesting objective in its own right. But this will not be undertaken here.
} 
feature on $V$ (i.e., below $v$ ), this will not happen. This feature will check the [pass] feature on Asp, and this will be acceptable syntactically, even though the syntax is active. Of course, only deponent verbs will be inserted into $\checkmark$ [pass]. It thus follows that only deponent verbs will have perfect participles in active syntax. ${ }^{42}$ On the second treatment, (37) will simply be violated if the syntax is not passive or if a deponent verb is not present.

\subsection{Syntax, Roots, and Features}

The morphological treatment of [pass] presented in section 5.1 is able to capture the behavior of the feature [pass] without syntactic complication, and it maintains Feature Disjointness; but it requires a theory in which syntaxlike movement takes place in the morphology or after. The treatment of [pass] as an uninterpretable syntactic feature allows for the forms of the perfect and the behavior of deponents to be captured mechanically; it also maintains Late Insertion of Roots and Feature Disjointness. Yet it does so at the expense of complicating the syntax, with the additional point that the complication is forced by the assumption that Roots are not present in the syntax. I therefore presented an alternative solution to the problem, in which (at least the deponent) Roots are visible in the syntax. This treatment is merely one implementation of the "Early Insertion'” approach. The point to be stressed is that considerations of Feature Disjointness are waived under treatments of this type. ${ }^{43}$ The arbitrary features of Roots can have a clear effect on the subsequent syntactic derivation. If this is the case, then the question that must be asked is along the following lines: if Root-specific features like [pass] can play a role in the syntax, then is the same true of purely phonological properties of Roots? Or semantic features? There is nothing in the architecture of the theory to preclude these possibilities.

What is at issue is the status of what is represented in the syntax with Roots. It could be the case, for instance, that the Root is represented simply with a label-that is, as $\sqrt{369}$, where this label is realized uniquely with phonological features, postsyntactically. In this representation phonological properties of the Root would not be visible in the syntax; but other features, which might affect the syntax, would be. A treatment of Roots along these lines is accountable to other factors. For instance, the implementation of a particular theory of suppletion, presented in Marantz 1995, relies on the idea that Roots are subject to Late Insertion. Marantz holds that suppletion is impossible for true Roots; the reasoning is that the entry for a suppletive Root, with a contextual condition on its insertion, would necessarily block all "normal" Roots from appearing in the

\footnotetext{
${ }^{42}$ The present participle behaves differently: Latin has no passive present participles at all, although it does have active present participles (e.g., from laudō 'praise', lauda-ns 'praising'; with deponents, e.g., hortor, horta-ns). The restriction here is again syntactic: no passive syntax in present participial syntax. Notice that if deponents like morior 'die' are treated as unaccusative, then unaccusative syntax is allowed in the present participle structure: moriens 'dying'. Of course, how restrictions of this type may be reduced to other syntactic principles is an open question.

${ }^{43}$ At least in part. Recall that Feature Disjointness has two directions: (a) arbitrary morphological/phonological properties do not affect the syntax; and (b) syntacticosemantic features are not reinserted in the morphology. The first is being questioned here. It is worth noting that the second direction makes distinct and interesting predictions about the interface as well.
} 
relevant environment. ${ }^{44}$ If this theory, which proceeds from the position that there is no suppletion for Roots, is correct, then the considerations presented above will have an effect upon its implementation.

Clearly the questions surrounding the Late Insertion of Roots are quite involved and require detailed investigations in a number of domains. But the discussion of this section clarifies several of the issues that are at stake. The reason that these issues are so clearly visible stems from the starting point of the investigation: Feature Disjointness, a strong position on the nature of features and the interfaces of syntax. As a result of operating in terms of this hypothesis, we now have a situation in which the boundary conditions for further attempts to refine the architecture are provided by both syntactic and morphological considerations. Ultimately, many of these issues are empirical; and they will only be resolved with the careful analysis of additional cases, assessed in conjunction with the case presented here. Recalling that the interest of the Latin case emerges as a result of proceeding with the most restrictive hypothesis concerning Roots and syntax, namely, Late Insertion and its correlate Feature Disjointness, the path is relatively clear. Specifically, even if one is willing to countenance Early Insertion in this case, one must proceed with the assumption that features of Roots are not syntactically active, absent a demonstration to the contrary. Under this stance, the Root properties that are absolutely required to be visible in the syntax will be made clear; and this will allow for a more detailed theory of how Roots, syntax, and morphology relate to one another.

Restricting attention now to the Latin perfect, there is a factor that unites the treatments given for Latin; on each approach the point that distinguishes the analytic and synthetic perfects is ultimately structural and concerns movement to $\mathrm{T}$ in one case, but not in the other. I therefore turn now to the realization of the forms of the perfect and the implications that this analysis has for notions of category.

\section{Category}

The analysis of the analytic/synthetic split above relies on the idea that the appearance of a participle in the analytic perfect is not the result of a participle-specific operation. Rather, the two are realized in the same basic structure, with movement to $\mathrm{T}$ in one case (synthetic), but not in the other (analytic). The claim is that the formation of the participle then follows from principles of Latin morphology, specifically, those concerning the spell-out of functional categories containing syntacticosemantic features. In this section and the next I provide an explicit treatment of these principles. ${ }^{45}$

44 Thus, for instance, if the plural form of $d o g$ were hound-s, the following entry would be required:

(i) $\sqrt{ } \leftrightarrow$ HOUND / [pl]

This is more specific than the entry for normal, nonsuppletive Roots and would thus preclude their insertion into the [pl] environment; it would thus be impossible to realize the Root (e.g.) $\sqrt{\text { CAT }}$ in the context of [pl], because the entry in (i) would always win the competition.

${ }^{45}$ Before proceeding with this, I will point out that this treatment, as well as the arguments presented above, follow for the Latin perfect. The status of the perfect crosslinguistically is an entirely different matter. In languages such as English, in which the perfect is always analytic, arguments of the type presented above simply cannot be formed. 


\subsection{Categories and Roots}

The analysis I have presented provides evidence for a syntactic theory in which simple category labels like $\mathrm{V}$ and $\mathrm{A}$ are irrelevant. Recall that the information required to determine which type of perfect is to be formed is localized in the feature [pass]. Based on the effects of [pass], the two types of perfect differ only in the position to which the $\sqrt{ }-v$ complex has raised in the tree: to Asp in one case (31), beyond Asp to $T$ in the other (30). Otherwise the two structures are identical, containing the functional heads T-Asp- $v$. The fact that distinct categories are found in the two perfects, auxiliary + participle (A) in one case, $\mathrm{V}$ in the other, shows that identical clausal structures may lead to distinct surface categories. ${ }^{46}$ That is, there is no difference in labels of the type $\mathrm{V}$ for verb, A for adjective ( = participle), or some decomposition resulting in these. What this means is that labels of this type are merely convenient tags for morphosyntactic notions: $V=$ root combined with tense, $N=$ Root combined with case/number/gender, $A=$ Root combined with case/number/gender, with the number and gender (and case) coming from elsewhere. ${ }^{47}$ Whatever utility these labels might have as shorthand, the point is that the Roots bear no simple substantive features on a syntacticosemantic level corresponding to these morphological notions of category. The differences in the objects listed above, the different "parts of speech," must therefore be reduced to other factors.

The argument that category is a notion relevant only in the morphology converges with the "category-free" treatment of nominalizations found in Marantz 1995, 1997. Marantz argues that underlying parts of speech like verb (e.g., destroy), noun (destruction), and so on, is a Root $(\sqrt{\text { DESTROY }})$, which is unspecified for syntactic category. ${ }^{48}$ In this implementation part-of-speech labels are relevant only in the morphological component. That is, a noun is a Root in a local relationship with a particular functional head, D. The functional heads are identifiable in terms of their syntacticosemantic feature content and thus play a defining role in the morphological realization of Roots. In what follows I will implement an analysis in terms of Roots of this type; the goal is to reduce the differences associated with part-of-speech labels like N, V, and A to differences in structural environments and morphological processes applying to Roots. That is, I will derive the effects of differences in morphological category without assuming a simple syntactic featural difference of the $\pm \mathrm{N} / \pm \mathrm{V}$ type in the first place.

\subsection{The Synthetic Perfect}

Recall that when [pass] is not present in the perfect, the Asp complex incorporates into T, as it does in other tenses. This is illustrated in (38).

\footnotetext{
${ }^{46}$ This is not meant to imply that participles are always realized in structures identical to those found with finite verbs; rather, they may sometimes appear in such structures, as well as in structures in which finite verbs do not appear.

${ }^{47}$ In terms of Latin morphology, the statement of these classes takes the following form. Agr nodes that are attached to [finite] $\mathrm{T}$ agree in terms of person/number. All other elements bearing an Agr-type desinence, whether classified as nouns, adjectives, or participles, will show gender/number/case suffixes, further conditioned by declensional class features. This is completely general, as adjectival endings are a subset of the nominal endings in Latin.

${ }^{48}$ For the background of this type of approach to nominalizations, see Chomsky 1970.
} 
(38)

\section{Synthetic}
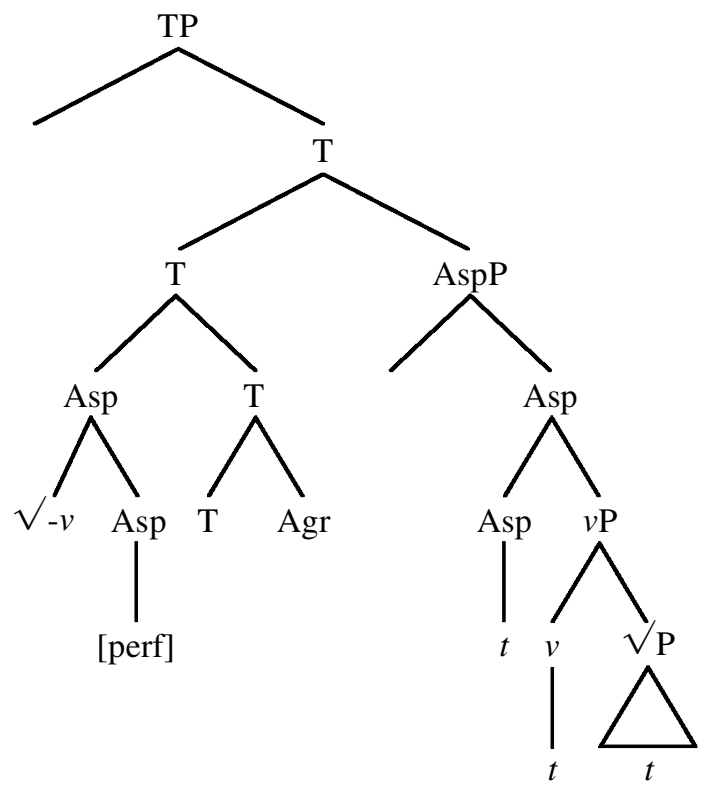

The realization of the finite perfect in this structure involves Asp with the feature [perf] being spelled out in a number of ways, as detailed above (see footnote 7). For instance, with the relatively frequent $-v$ - and $-s$ - suffixes for the perfect, the following spell-out rules are relevant:

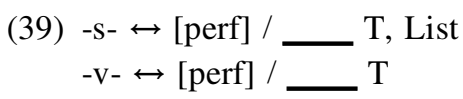

Other conditions specifying the other allomorphs of the perfect can be stated similarly. The point is that these spell-out rules are specifically tailored to the circumstance in which Asp is in a complex merged with T-Agr. This will separate these cases from cases in which Asp is not combined with $\mathrm{T}$, which are realized as the analytic perfect. ${ }^{49}$

\subsection{Realization of the Analytic Perfect: Initial Points}

The questions to be addressed now center on the analytic perfect; recall that this is realized in the structure shown in (40).

${ }^{49}$ Previous analyses, as well as some traditional discussions, have argued that the synthetic forms of the perfect have a suffixed form of esse 'be' in them (see, e.g., Lindsay 1915, Giorgi and Pianesi 1991, 1997). If this were correct, it would be compatible with the treatment $\mathrm{I}$ have given, in the sense that it would point to a direct relationship between the two types of perfect. However, I believe that the evidence actually shows that esse is not suffixed in the synthetic perfect forms.

The argument in favor of a suffixed-'be' treatment is based on additional forms of the perfect: the pluperfect and future perfect. I will focus on the pluperfect here, as the future perfect is equivocal from the perspective of the two approaches to be considered. The pluperfect forms of amō, along with the imperfect forms of sum 'to be', are as follows: 
(40) Perfect without movement of $\sqrt{ }-v$-Asp to $T$

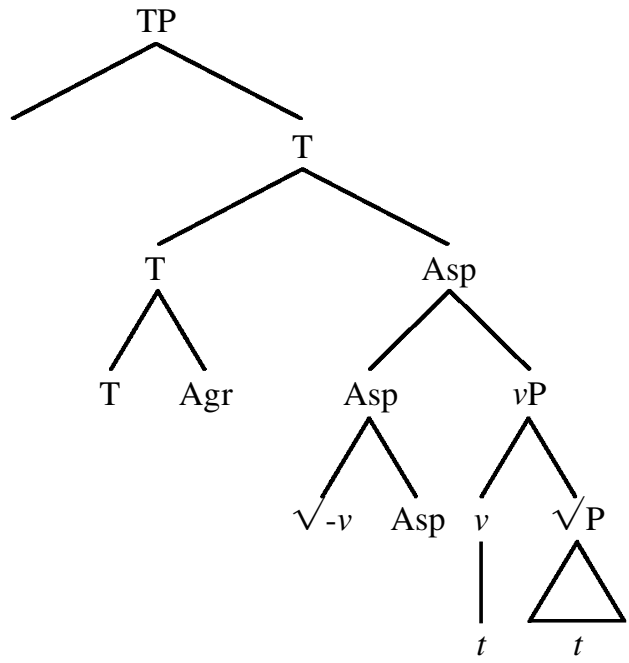

(i) Pluperfect active

1sg. amā-v-er-am

2sg. amā-v-er-ās

3sg. amā-v-er-at

1pl. amā-v-er-āmus

2pl. amā-v-er-ātis

3pl. amā-v-er-ant
'I had loved'

'you had loved'

'he/she had loved'

'we had loved'

'you had loved'

'they had loved' (ii) Imperfect of sum

$\begin{array}{lll}\text { 1sg. } & \text { er-am } & \text { 'I was' } \\ \text { 2sg. } & \text { er-ās } & \text { 'you were' } \\ \text { 3sg. } & \text { er-at } & \text { 'he/she was' } \\ \text { 1pl. } & \text { er-āmus } & \text { 'we were' } \\ \text { 2pl. } & \text { er-ātis } & \text { 'you were' } \\ \text { 3pl. } & \text { er-ant } & \text { 'they were' }\end{array}$

The pluperfect forms thus appear to have a past tense form of 'be' (eram, etc.) suffixed to the stem $+-v$ - (cf. (49)). Like the perfect, the pluperfect passive involves the $-t-/-s$ - participle with the imperfect of 'be': amā-t-us er-am. In this way, the pluperfect active appears to be a (phonologically slightly different) parallel to what happens in the perfect and pluperfect passive - that is, it appears to include an overt form of 'be' that happens to be collapsed with the stem in a way not found in the passive.

There are two points to be made concerning this suffixed-'be' analysis. The first is diachronic: it is not the case that the element -er- appearing on the perfect stem in the pluperfect is derived from the verb 'be'. The forms of 'be' that show - $e r$ - are derived from the stem es- via the process of rhotacism $(s>z>r)$. But the relevant component of the pluperfect can be shown to be derived not from es-, but from a component -is- (for details see Sommer 1914, Leumann, Hofmann, and Szantyr 1963). The surface appearance is similar to that of 'be' owing to the operation of similar phonological processes (in the case of -is->-er-, rhotacism and the additional lowering of the vowel). For a discussion of the history of -is-, see Leumann, Hofmann, and Szantyr 1963:sec. 444; for rhotacism, sec. 180; for the vowel change, sec. 86.III.

The second point is that there are synchronic differences between the element appearing after the perfect stem in the pluperfect and the verb 'to be'. In the imperfect subjunctive the form of 'be' is based on the stem es-: essem = 1sg. imperfect subjunctive. The 1sg. form of the pluperfect subjunctive, on the other hand, is ama vissem (i.e., with -is- and not -es-). No phonological process can be held accountable here for the difference, as there is no basis for raising /e/ before /ss/. So, the pluperfect subjunctive, if it actually included a form of 'be', would be *amāvessem; but it is not. I therefore conclude that the pluperfect active is like the perfect active, with an additional element -er-/-is-. Thus, despite surface appearances, the pluperfect active does not necessarily give special insight into the structure of the perfect as a whole. Giorgi and Pianesi (1997) propose an alternative to the -is- account of the pluperfect, acknowledging that their incorporation solution is controversial. I will retain the more conservative treatment here, barring any further developments in support of the incorporation hypothesis.

In any case, the important point is that the account offered here differs from Giorgi and Pianesi's approach crucially in terms of the point at which analytic and synthetic perfects diverge: based on passive syntax for Giorgi and Pianesi's treatment, but based on the morphological feature [pass] here (recall section 3). As long as this difference is clear, questions concerning the presence or absence of something related to 'be' in the synthetic perfect are of secondary interest. 
This breaks into two components. The first has to do with the T-Agr complex, and the second with the $\sqrt{ }-v$-Asp complex. Beginning with T-Agr, the appearance of esse 'be' can be attributed to a sort of default instantiation of tense. However, this is different from $d o$-support, in that it is not directly triggered by agreement/finiteness. That is, whereas there is no do-support in infinitives, where there is never overt tense/agreement to be supported, Latin 'be' appears in infinitival forms of the analytic perfect: laudātus esse 'to be praised'. 50

The morphology found in the participle is more complicated, as it does not directly instantiate voice features like [pass] or aspectual features like [perf]. Rather, it is the default realization of the head Asp. To see this, an excursus into Latin deverbal formations is necessary.

The Latin participle that appears in the perfect, the so-called perfect passive participle, shows unpredictable allomorphy between $-t$ - and $-s$-. Thus, consider laud-a- $-\underline{t}-u s$ 'praised' (infinitive laud-ä-re) and ius-s-us 'judge' (infinitive $i u b-\bar{e}-r e$ ); here - $t-/-s$ - are the "participial" affixes, and $-u s$ is the gender/case/number desinence. I will refer to the former pair of exponents, as found in the perfect and forms to be discussed below, as $-t-/-s$ - throughout the remainder of the discussion. The main complications arising with $-t-/-s$ - stem from the fact that they have a default status in the derivation of deverbal formations (in this I follow Aronoff 1994; see below). A long-standing problem in the analysis of Latin participles is the fact that the future active participle (e.g., laudā$t-\bar{u} r$-us 'about to praise') shows, in addition to the $-\bar{u} r$-component, allomorphy identical to that found in the perfect participle (as well as in other forms, such as the supine, and various nominalizations). ${ }^{51}$ At the same time the two differ in voice. The problem comes from an attempt to treat the past and future participles in a uniform way. The forms of the two participles for $a m \bar{o}$ are as follows:

(41) Past participle: am-ā-t-us 'loved'

Future active participle: am-ā-t-ūr-us 'about to love'

Allomorphy in these two participles, between $-t$ - and $-s-$, is both identical and phonologically nonpredictable, throughout a number of distinct deverbal formations. The forms with $-s$ - were originally merely variants of the $-t$ - suffix conditioned by regular morphophonological factors (the $-s$ - appeared originally with stems ending in dentals). However, the $-s$ - suffix spread to forms in which it could not have been brought about phonologically from - $t$-, making it a true allo-

${ }^{50}$ English does, however, require have with the infinitival perfect. It should be noted that the discussion here is meant to apply exclusively to the appearance of esse in the Latin perfect.

Verbal support of this type might be reduced to the requirement that $\mathrm{T}$ be combined with a $v$ element, realized as the "default $v$ " esse. In such a case the support of T provides a further argument in favor of the syntactic solution developed above. If $\mathrm{T}$ support were morphological, then the morphology would be forced to introduce a default $v$ on $\mathrm{T}$, to be realized as esse. But $v$ is a syntacticosemantic object. Introducing it in the morphology would require a system in which morphology has the ability to introduce objects relevant only in syntax/semantics, an undesirable consequence given the idea that Feature Disjointness should be maintained to the fullest possible extent; that is, having the morphology insert $v$ would be a violation of the second direction of Feature Disjointness.

${ }^{51}$ See Benveniste 1948 for the latter types. As noted, the problem is not restricted to the participles; the same allomorphy noted below occurs in other types of adjectives and nominalizations. I will concentrate here on the "past passive" and "future active" participles, as the point may be seen clearly in this contrast. The theoretical questions raised by the behavior of the "past passive" and "future active" participles have been discussed at least since Matthews 1972. 
morph. ${ }^{52}$ Thus, the realization of the $-s$ - or $-t$ - component will be the same in the perfect and the future active, even with verbs that have irregular participial forms. ${ }^{53}$ Thus (cf. Aronoff 1994):

\begin{tabular}{|c|c|c|c|}
\hline $\begin{array}{l}\text { Verb } \\
\text { vehere }\end{array}$ & $\begin{array}{l}\text { Perfect part. } \\
\text { vec-t-us }\end{array}$ & $\begin{array}{l}\text { Future active part. } \\
\text { vec-t-ūr-us }\end{array}$ & $\begin{array}{l}\text { Translation } \\
\text { 'carry' }\end{array}$ \\
\hline iubēre & ius-s-us & ius-s-ūr-us & 'order’ \\
\hline premere & pre-ss-us & pre-ss-ūr-us & 'press' \\
\hline ferre & lā-t-us & lā-t-ūr-us & 'bear' \\
\hline
\end{tabular}

The problem is thus as follows. In one type of analysis of the future perfect, an affix $-\bar{u} r$ is added to the perfect participle. However, the two participles differ in voice (in the normal case): the past participle is passive; the future is active. As noted, this is part of a more general problem: the question of $-t-/-s$ - allomorphy arises in a number of deverbal formations. Aronoff (1994) argues convincingly that there is no coherent morphosyntactic content, in terms of voice or aspect, to be associated with $-t-/-s$-. This basic position is one that I will adopt here. ${ }^{54}$ Specifically, in the next section I will implement an analysis according to which $-t-/-s$ - are the default instantiations of a functional head found in "deverbal" syntactic objects. In doing this, I will use the abbreviation Default-Asp to refer to the conditions under which the exponents $-t-/-s$ - are realized on Asp.

\subsection{Deverbal Formations}

There are two questions that must be addressed in analyzing the "past passive participle," based on the idea that the participle is a type of "deverbal" formation. First, the status of a notion like "deverbal" must be captured in a theory without categories like "V" in the first place. Second, the actual realization of the perfect with the affixes $-s$ - or $-t$ - must be addressed. The analysis that I present links the deverbal status of the relevant forms directly to the behavior of the exponents $-t-/-s-$. What it means for something to be deverbal in this sense is that it appears beneath the functional head Asp (and perhaps $v$ as well), but not combined with T. The motivation for positing the head Asp in such cases lies in the syntax and semantics as well, in that aspectual properties are implicated in nominalizations and other deverbal formations. The affixes $-s$ - and $-t$ - are then the default realization of this aspectual head, and this accounts for their distribution.

To begin with, realization as the morphological object $\mathrm{V}$ amounts to combining (through head movement or Merger) with T. This combination could fail to occur for more than one reason.

\footnotetext{
${ }^{52}$ Some attempts have been made to account for this extension of the $-s$ - form; thus, for instance, Sommer (1914: 607) suggests that the presence of verbs with perfects in $-s$ - (e.g., scrib- $\bar{o}$ 'write', perf. scrip-s- $\bar{l})$ facilitated the spread of the $-s$ - participle.

${ }^{53}$ As Aronoff notes, there are exceptions to this, but not for $-t-/-s-$; rather, there are a few verbs in which the phonology of the Root + Theme preceding $-t-/-s-$ is different in the two cases. Thus, for instance, the (deponent) verb

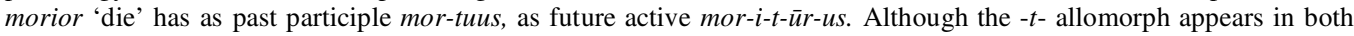
cases, the two participles show other differences.

${ }^{54}$ Aronoff derives further conclusions from this point that I do not accept; see section 8 for some discussion of his framework.
} 
In nominalizations $\mathrm{T}$ will not be present ${ }^{55}$ rather, the functional head D will ultimately dominate the position of the Root (although Asp will be present). In the perfect with the feature [pass], there will be no combination of the $\sqrt{ }$ - $v$-Asp complex with $T$. Effectively, then, a deverbal noun or adjective is a Root appearing in the structure in (43), when this structure does not combine with $\mathrm{T}$ (although other functional heads might be present). Specifically, I propose that deverbal formations share as a subcomponent the piece of tree shown in (43).

\section{Common structure of deverbal formations}

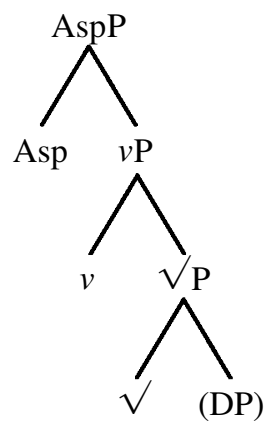

Recall that the head $v$ here is the functional "light verb" and that the head Asp contains features relating to perfectivity and imperfectivity. Taken together, the two functional heads here contain basic information about eventivity/stativity, along with further aspectual information about the status of the event or state. Depending upon which functional heads appear higher up in the structure, the resulting object will be an "A" or an " $\mathrm{N}$," if it does not combine with $\mathrm{T} .{ }^{56}$

In this structure - $t-/-s$ - are default instantiations of the head Asp. ${ }^{57}$ This follows the first part of the analysis presented in Aronoff 1994; -t-/-s- have no consistent content in terms of voice, aspect, and so on. Rather, the common property of forms with these exponents consists in their simply being deverbal, and not something more specific than this. When there is a more highly specified vocabulary item with a proper set of features, such as the present participle in -nt- (cf. laud- $\bar{a}-\underline{n s}$ 'praising'), ${ }^{58}$ this will prevent insertion of the defaults (see (44)).

There are two further components to analyzing the behavior of $-t-/-s$ - in terms of this structure. The first has to do with what determines the choice between these two for a particular verb. This is simply a listed property of these vocabulary items, unconnected with deeper generalizations. ${ }^{59}$ The Asp node in the tree will always be specified for features like [perf] and [pres]; but for the

${ }^{55}$ Or will be dominated by $\mathrm{D}$, and affected accordingly. Certain approaches do in fact posit $\mathrm{T}$ within the DP.

${ }^{56}$ For instance, in the nominalizations (e.g., the supine) a D will be present.

57 The default status of "perfect" participial morphology also surfaces in Ippolito's (1999) analysis of Italian and Arregi's (1999) analysis of Basque, suggesting further crosslinguistic questions that I cannot pursue here.

${ }_{58}$ The $-n t$ - suffix is realized in the (nominative singular) citation form as $-n s$.

${ }^{59}$ As noted earlier, allomorphy between $-t$ - and $-s$ - is not phonologically predictable, although it was originally (see, e.g., Sommer 1914, Ernout 1952/1989); hence the list here. Having an $-s$ - as opposed to $-t$ - in this object does not correlate with other types of allomorphy (e.g., in the synthetic perfect). Thus, there are forms with $-s$ - in the synthetic perfect, like $s c r i b-\bar{o}$ 'write', perf. scrip-s- $\bar{l}$, with $-t$ - participles: scrip-t-us 'written'. At the same time there are verbs with $-s$ - participles, but not $-s$ - perfects: fall- $\bar{o}$ 'deceive', perf. fe-fell- $\bar{l}$, participle fal-s-us. 
realization of Default-Asp, what is required is underspecification of the vocabulary items, such that the $-t$ - or $-s$ - will appear when no more specific instantiation of Asp can be inserted. Thus, at least the following vocabulary items will be relevant, where the conditions for the insertion of the present participle - $n t$ - affix are given for purposes of exposition:

$$
\begin{aligned}
& \text { Realization of Asp (not raised to T) } \\
& \text {-nt- } \leftrightarrow \text { [pres] } \\
& - \text {-s- } \leftrightarrow[\text { ] } / \text { (List) } \\
& \text {-t- } \leftrightarrow[\quad]
\end{aligned}
$$

The second component has to do with adjustments to the stem of the verb that take place in the deverbal $-t-/-s$ - forms. In a number of cases the phonology of the stem of the verb is different in present, perfect, and past participle environments. Thus, for instance, in the "nasalinfixing" class, there are sets like tang- $\bar{o}$ 'touch' with perfect $t e-t i g-\bar{\imath}$, participle $t \bar{a} c-t-u s$. On the view I am assuming here, stem allomorphy of this type is distinct from affixation. It results from what Halle and Marantz (1993) classify as readjustment rules, morphophonological processes that apply to alter the shape of stems. In particular, the point is that the certain phonological readjustments to the stem could be tied to the presence of $-t-/-s-$. When a more highly specified affix wins out over $-t-/-s-$, there are no apparent effects on the phonology of the stem. In traditional terms, this is expressed by saying that certain participial forms (e.g., the present, the gerundive, gerund) are based on the "present stem." Ultimately this may or may not be the result of there being phonological effects associated with consistent sets of features in the environment of the stem. $^{60}$

Summarizing the approach, the conclusion is that $-t-/-s$ - are the default realization of an Asp head, which is a component common to the various deverbal structures. ${ }^{61}$ The appearance of these exponents in both the "past passive" and "future active" participles presents no contradiction; each of the structures associated with these two participles contains an Asp head, which is realized with the default affix. In the case of the future active, I assume that additional structure is present, pertaining to the modal nature of the interpretation 'about to . . ${ }^{62}$ The two structures, shown with the relevant exponents in the positions that they instantiate, are given in (45) and (46).

${ }^{60}$ For instance, the present and perfect systems could be divided along Varro's distinction infectum versus perfectum (see Varro 1938; essentially imperfective versus perfective, but see Binnick 1991 for discussion and a critique of this classification). This would accord with the fact that stem suppletion is conditioned by this distinction, in fer- $\bar{o}$ 'carry' in imperfective tense/aspects, $t u l-\bar{l}$ in the (synthetic) perfect. It should also be noted that adjustments to the stem are associated with the synthetic perfect; see footnote 7 .

${ }^{61}$ The syntactic analysis discussed to this point involves two distinct heads, $v$ and Asp, which are crucially involved in defining deverbal status. In a number of cases aspectual specification and the licensing of agents are intimately connected with one another. For instance, the generalizations associated with the distinction between "adjectival" and "verbal" passives made, for example, by Wasow (1977) are largely restatable solely in terms of aspect: stative versus eventive (see Pesetsky 1995, Marantz 1995). How these connections between aspect and agentivity/etc. are to be captured is an interesting question, but one I cannot address here.

${ }^{62}$ I take it as uncontroversial that modal information appears in deverbal structures of this type; witness, for example, the so-called gerundive of Latin: from laud-o 'praise', there is the gerundive laud-a-nd-us '(one) to be praised', with the necessitative interpretation of English "modal be" (John is to be praised). 
(45)

"Past passive"

(example: $a m-\bar{a}-t-u s)$

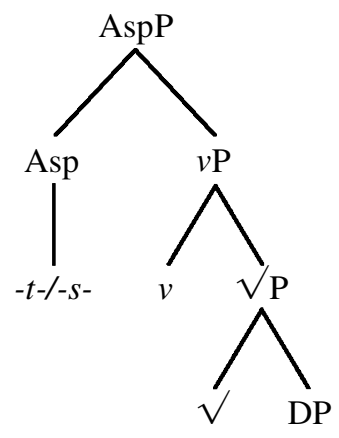

(46) "Future active"

(example: $a m-\bar{a}-t-\bar{u} r-u \grave{s}$

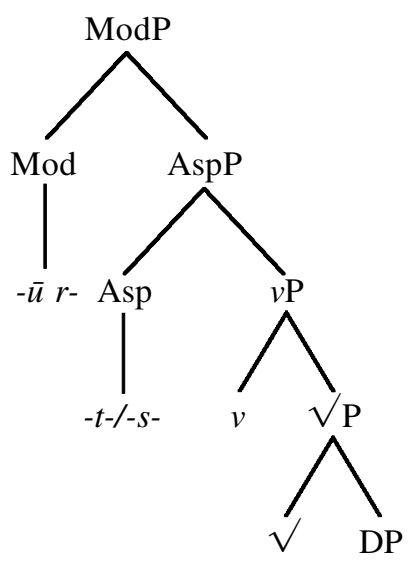

The examples here indicate the surface forms that will be realized following head movement of the $\sqrt{ }-v$ to Asp or Mod in each of these cases.

Further questions, concerning what precisely makes the second of the two participles above active as opposed to passive syntactically, are part of a much larger set of issues concerning correlations between voice, aspect, and syntactic structure that I cannot hope to address here (cf. footnote 61 ).

\subsection{Other Aspects of Default-Asp}

In addition to there being participles in $-t-/-s$ - formed from Roots with verbal forms, there are those that apparently take the "participial" ending - $t$ - (Allen and Greenough 1931:149, Gildersleeve and Lodge 1895:130; also see Joffre 1986), but for which no verbal forms are found; that is, these Roots do not appear as verbs, combined with $\mathrm{T}^{63}$

(47) fūnus 'death': fūnes-t-us 'deadly'

honor 'honor': hones-t-us 'honorable'

barba 'beard': barb-ā-t-us 'bearded'

turris 'tower': turr-1-t-us 'turreted'

cornū 'horn': corn-ū-t-us 'horned'

The interpretation is something like 'provided with'. Unlike what we found with the participles in $-s-/-t-$, however, there are no verbal forms for these Roots, which are otherwise realized in nominal environments. This connects with a further fact about "perfect passive participles." Although the participles are in many cases interpreted as having perfect/perfective aspectual

${ }^{63}$ Because there are no verbal forms, we cannot establish the abstract identity underlying this affix as we could with Default-Asp $-t-/-s$ - in the deverbal formations discussed above. 
properties, this is not always the case; thus, Brugmann (1895:secs. 4, 7) observes that $-t-/-s$ adjectives appear with both present and perfect interpretations. ${ }^{64}$

(48) a. maerē̄ 'be sad, grieve', maes-t-us 'full of sadness, sorrowful'

caveō 'be on one's guard', cau-t-us 'cautious'

tacēo 'be silent', taci-t-us 'silent'

b. vir laudātus 'man being praised'

filius ūnicē amātus 'especially loved son'

vir ab omnibus contemptus 'man despised by all'

regiō habitāta 'inhabited region'

The "dual function" of the same form is explained by Brugmann (1895:94) as resulting from the fact that both are essentially predicates and that the "adjectival" use of the form denoted a characteristic property, which was, like the participial use, in some sense complete. Joffre (1986) seems to be getting at something similar in identifying - $t$ - adjectives and participles as describing a state that is "non dépassé" ("not passed'; i.e., presumably one that simply holds). Given the status of $-t-/-s$ - as default realizations of Asp, these facts are less surprising. Stativization as construed in a broad sense can apply to eventive verbs, stative verbs, and "nouns" alike. In the case of the derivation from the Roots in (47), the idea is that to be provided with a quality denoted by the Root is in some sense an aspectual notion. Thus, the fact that "participial" morphology should appear on Roots that do not appear as finite verbs becomes somewhat less obscure. Although the question of the nonoccurrence of such forms as verbs is still open, the discussion of this section points to a direct connection between the properties of Asp and the properties of the functional structure associated with "adjectives." ${ }^{65}$ The absence of verbal forms might then stem from the fact that stativizing Asp, spelled out as - $t$-, applies syntacticosemantically in a wide range of environments.

That is, there are features of Asp that function quite generally on a syntacticosemantic level as stativizers; but these are always realized with the default realizations of Asp - $t-/-s-$, even when the features apply to different complements. This would account for the variable interpretation of the "participles," as well as the behavior with Roots that do not form verbs. The absence of verbal forms in the relevant cases would then be acceptable; the appearance of a Root in the stativized structure does not necessarily imply that the same Root will function independently as a "verb." But the conclusion must remain speculative, as there is in the case of the Roots in (47) no argument for the morphologicalidentity of the - $t$ - with that found in deverbal formations. ${ }^{66}$

${ }^{64}$ This, for Brugmann, was the difference between a deverbal adjective, which is aspectually indifferent, and a participle, which is aspectually specified. The aspectual (= Aktionsart) properties of the underlying verbs also play a role, as Hofmann, Leumann, and Szantyr (1963:391) note.

${ }^{65}$ For the question of what might underlie the apparent gaps of this type, see Ippolito's (1999) analysis of Italian participial formations.

${ }^{66}$ The overlap between denominal and deverbal adjectives might be found in English as well, with denominal adjectives meaning 'provided with' formed with "participle" endings.

(i) a. beard: bearded

horn: horned

wing: wingèd 


\section{Comparison with Lexicalist Treatments}

I now address possible Lexicalist and syntactic approaches to the phenomena analyzed above. The term Lexicalist here refers to theories of the type developed in Lieber 1980, Kiparsky 1982, Di Sciullo and Williams 1987, and related work, whose defining property for present purposes is that affixation in a presyntactic lexicon determines syntactic behavior. That is, on this type of theory affixes exist in a lexicon like everything else; the properties for which an individual affix is specified determine the behavior of complex words through mechanisms governing the inheritance or "percolation" of features. Thus, to take a very simple example, the English plural morpheme would consist of the following, along with a specification of the phonological shape (viz., /-z/):

(49) $[[\mathrm{N}][-\mathrm{z}[\mathrm{pl}]]]$

The $[\mathrm{pl}]$ feature becomes a feature of the entire derived word, now a plural noun. The same type of consideration applies to more complex cases, for example, passives. The formation of a passive verb is directly related to affixation with "passive morphemes," and this produces passive syntax.

To begin with, a Lexicalist approach to deponent verbs faces a very general problem, even without something like the Latin analytic/synthetic split. This is discussed in detail in Embick 1997, 1998; I will summarize the major points of those treatments here. The major objection concerns how deponents would have to be specified on a Lexicalist treatment in the first place. On a Lexicalist approach affixation determines the syntactic behavior of the affixed word. Affixation of passive morphology will result in verbs that may appear only in passive syntactic environments; that is, in this type of theory affixation of passive morphology will, in effect, force a passive syntactic configuration. Deponent verbs have passive morphology. But deponent verbs of the type discussed above do not have passive syntax. Thus, the morphology found in deponents and that found with passive verbs cannot be the same in terms of its morphosyntactic features. One set has to produce passive syntax; the other set has to be simply associated with a lexical quirk. Yet this misses significant generalizations. Passives and deponents are morphologically identical through all tenses, persons, and so on, and moreover behave the same way with respect to the formation of the perfect. In a Lexicalist theory, however, the most that can be said is that there are two distinct sets of affixes found with passives and with deponents, which, despite being

\footnotetext{
b. tooth: saber-toothed hair: long-haired tail: bushy-tailed
}

The (b) examples are only possible with further modification (i.e., *haired); see Marantz 1989 for discussion of similar cases. As far as this connection goes in English, there is a further complication. In some cases the denominal adjectives with -ed require a syllabic pronunciation of the suffix: thus, wingèd in (ia). Dubinsky and Simango (1996) note that the reason for this lies in the fact that historically two distinct - ed suffixes are involved here. They note further that for certain verbs, there are two pronunciations of the -ed suffixed forms: for example, /blest/ and /blessèd/ for bless. The former is for them a verbal passive, the latter adjectival. The main thrust of their argument concerning these forms is directed against the position taken in, for example, Levin and Rappaport 1986 (and earlier work) that adjectival passives are zeroderived in the lexicon from verbal passives. However, many instances of this type appear to be adjectives without the aspectual force of the "adjectival" passive, rendering the status of Levin and Rappaport's argument unclear. 
phonologically identical in all cases, have distinct morphosyntactic features. The identity of the two types of verbs, captured here with the single feature [pass], is completely missed on this type of treatment.

Having noted the above, I should point out that the behavior of deponent verbs could always be stated formally in a Lexicalist theory. It could be argued, for instance, that although certain types of "passive morphology" propagate features associated with passive syntax (or project "passive syntax"), the same is not true of passive morphology with a lexically specified set of verbs, the deponents. In formal terms this is, of course, a possibility. The point is that this type of analysis results in a stipulation in a component of the grammar that determines syntactic behavior. On this type of theory, the behavior of complex words is determined in the lexicon; the fact that phonologically identical sets of affixes have radically different syntactic effects can then only be captured as a stipulation, and one that strips away the idea that lexical processes determine syntax. On the other hand, treating voice features like [pass] as identical in both cases, as on the present account, captures the relevant syntactic effects (analytic vs. synthetic forms), without losing the identity of the feature in both passive syntax and deponent verbs.

\section{Syntax and Paradigms}

\subsection{Paradigmatic Perspectives on Syntax and Morphology}

The split behavior of the Latin perfect might be seen as supporting a "paradigmatic" approach to morphology. Paradigmatic approaches are proposed by Matthews (1972) and developed and elaborated in Anderson's (1982, 1992) "extended word-and-paradigm" and "a-morphous" approaches. The most relevant property of theories of this type is that they allow for a great amount of laxity in the interface between syntax and morphology; syntactic distinctions and positions are potentially obliterated on the way to morphological realization. ${ }^{67}$ The reason for this is that "morphemes" have no status in theories of this type, beyond being the by-products of morphophonological rules. Associating specific signals with specific syntactic objects in a hierarchical structure is thus not possible. On the paradigmatic approach, sets of morphosyntactic features are associated with rule blocks. The rules are conditioned by the features, and any phonological material inserted onto a form is merely a by-product of the operation of the abstract rule. Because phonological pieces are simply by-products of rules, rather than the exponents of fixed positions in a structure built by the syntax, the possibility exists that morphological realizations will bear little relation to each other or to the syntactic structures in which these forms appear. The clearest example of this type of theory for present purposes is in the "morphology-by-itself" approach,

${ }^{67}$ There is also a type of paradigmatic approach to morphology, exemplified in the work of Carstairs-McCarthy, that differs from this type in many respects. Carstairs-McCarthy $(1987,1992)$ recognizes that an important goal of any morphological theory is to state and capture the constraints on deviation from one-to-one patterns in the relationship between syntax/semantics and morphology. In his approach the objects over which such constraints are stated are entire paradigms, that is, entire sets of inflected forms of lexemes. Thus, irrespective of how this "paradigm" relates to syntax, constraints are not stated at the level of features and their interactions, but on sets of inflected forms arranged in a certain way and considered as a privileged theoretical object. Börjars, Vincent, and Chapman's (1996) treatment discussed below appeals to an extrasyntactic notion of paradigm as well. 
elaborated by Aronoff (1994). Aronoff's theory posits a "fully mediated" syntax/morphology interaction. An intervening level exists between syntax and morphological realization, such that the differences between disparate syntactic objects can be completely removed prior to morphological realization (see Aronoff 1994:25). ${ }^{68}$

The existence of corresponding analytic and synthetic forms in Latin, along with the existence of deponent verbs, seems to point to discrepancies between syntax and morphology: in one case an unexpected difference in composition, in the other a problem with "passive" morphology without passive syntax. A theory with an intervening level mediating syntax and morphology, which syntactic structures can be related to arbitrarily, is able to accommodate this apparent mismatch quite easily. ${ }^{69}$

The problem with the paradigmatic view in the present case is that it can in principle make no predictions about what is realized in the analytic perfect. On this type of treatment, a $-t-/-s-$ participle is realized because a particular set of features happens to be associated with this object-that is, with a specific realizational rule, or with a particular "stem," as in Aronoff's treatment. But the analysis presented above shows that what is found in the analytic perfect follows predictably from a syntactic structure that is the same as the one underlying the synthetic perfect. The distribution of $-t-/-s-$, and its presence in certain forms but not others, follows from the default nature of these vocabulary items and from a structural analysis that is motivated by syntax and semantics. The analysis furthermore carries over to the range of deverbal formations in which the $-t / /-s$ - affixes appear. There is a separation between syntax and morphology on the approach advocated here. But the default case is for the morphology to instantiate terminals in syntactic structures, thus ensuring direct interaction. Paradigmatic theories like that proposed by Aronoff, on the other hand, emphasize this separation to the extent that direct interactions are at best a convenient accident. ${ }^{70}$ That is, the worst possible case, with erasure of syntactic distinctions in the morphology, is the norm, or at least not differentiated from the norm.

There is a second variety of paradigmatic approach to syntax/morphology interactions, in which a "paradigm space" generated outside of the syntax contains entries in cells that are correlated with morphosyntactic feature combinations. A specific paradigmatic treatment, part of which is directed specifically at the two forms of the Latin perfect, illustrates a number of points particularly well. Börjars, Vincent, and Chapman (1996), assuming that the two forms of the perfect must fill slots in the same paradigm, base their analysis on the idea that positions in a paradigm may be filled by syntactically complex objects. In essence this analysis makes the following claims: first, that there is an extrasyntactic space, the "paradigm," containing forms

\footnotetext{
${ }^{68}$ The loss of information between syntax and morphological realization in this type of theory is distinct from the neutralization of features in the morphology, that is, impoverishment in the sense of Bonet 1991 and subsequent work (see, e.g., Noyer 1992, 1998, Halle 1997). Impoverishment does not eradicate syntactic structures, only particular features. The possibility for complete erasure of syntactic distinctions thus does not exist.

${ }^{69}$ In principle it is capable of accommodating almost everything, subject perhaps only to considerations of learnability. But I will concentrate here on illustrating the difficulties presented by the perfect for this type of theory.

${ }^{70}$ In other paradigmatic theories the separation would not be as extreme; the focus here is on Aronoff's treatment for expository purposes.
} 
corresponding with feature values; and, second, that the objects in the paradigm may be syntactically complex, that is, have to be regarded as constructed by the syntax. With these two properties, this is a theory in which any relationship between syntax and morphology can simply be listed in tables; there are no interesting predictions to be made, because absolutely anything could fill a cell in a paradigm: any "word," any phrase, any sentence. Regular realization and suppletion are on exactly the same plane. ${ }^{71}$ As a result, the theory can in principle make no predictions about possible syntax/morphology connections. Although it is true that the occurring forms of the Latin perfect can be described in this notation, the account offers nothing beyond a recitation of the basic facts.

\subsection{Syntax and Separation}

The analysis I have presented above of the Latin perfect is, in its essence, syntactic. But treating the Latin perfect syntactically does not amount to ignoring the fact that it is a special case. There is, of course, something odd in this system. Owing to properties of Latin morphology, isolated in the feature [pass], the two types of perfect differ from each other on the surface. This is simply a vagary of Latin, the origin of which is ultimately diachronic. Yet despite this quirk, the two forms are not completely unrelated to one another. That is, the components of the analytic perfect result predictably in a perfect passive (or in a deponent, a perfect). On the paradigmatic view, that this should be the case is in no way ensured. Owing to properties of its specification, the "past perfect participle" does not contain vocabulary items that specifically contain the features [perf] and [pass]. This is due to properties of the specification of $-t-$ and $-s-$, that is, their default distribution. But their appearance is predictable given the structure that underlies the analytic perfect. Even with the differences in surface realization, the forms found in the perfect are consistent; and the consistency follows from a syntactic analysis.

Having noted the above, I must acknowledge that the Latin system represents a double departure from a direct model of syntax/morphology interactions, where "direct" refers to the simple case in which exponents are inserted into terminal nodes arranged by the syntax, and that is the end of the story. First, the voice system involves features like [pass], whose status is unclear. Second, the existence of deponent verbs represents a further departure, in which the same feature [pass], which is in one case systematically related to the syntax, is also associated inherently with certain Roots. But these departures are deviations from the normal state of affairs. In the treatment I have provided, the points of departure from the direct model are isolated and constrained, not generalized to overarching principles. The connections between structure and form in the Latin perfect may be complicated, but they are not random. At the heart of the matter, the syntactic and semantic identity of the structure resulting in the two perfects provides the basis common to the two forms.

\footnotetext{
${ }^{71}$ See Borrjars, Vincent, and Chapman 1996:159, where it is noted that in terms of their analysis " . . . a suppletive form and a regularly derived form have exactly parallel feature representations... Therefore, as far as the grammar is concerned, they behave indistinguishably from each other."
} 
On a more general level, the comparison of the paradigmatic and syntactic approaches to syntax and morphology suggests how theories of the syntax/morphology interface are to be constrained. All of the theories discussed in this section accept the Separation Hypothesis, the idea that there is a distinction between morphosyntactic features and the morphophonological exponents associated with them. The move to separation is required in order to account for basic facts about syntax/morphology interactions-in particular, for systematic neutralizations of features, requiring underspecification, and default vocabulary items. I will not trace the history or the full motivation behind this idea here; Beard 1995 contains relevant background discussion. The point is that a burden comes with this move. Separating syntax and morphology in this way raises questions about how and why the interaction between these two components is primarily direct - that is, why there are, for the most part, systematic correlations between syntax and morphology in the first place. The assumption that has driven this investigation is that the interface is constrained because, in the default case, morphology interprets syntactic structures directly.

\section{Conclusion}

In terms of what it presents for the study of verbs and participles, and for the study of category more generally, the Latin perfect is a special case. This is due to its mixed nature. As a result of this, it can be shown that analytic and synthetic forms derive from the same syntactic structure. What can be shown in this particular case contrasts with other cases in which one finds an auxiliary and a participle. In any auxiliary + participle formation, one could argue that the participle contains information (aspectual, etc.) not associated with regular adjectives. This much is clear. But it does not specify the manner in which the "adjectivalization" of verbs occurs. Nor, for that matter, is the relationship between the auxiliary + participle forms and other synthetic verbal forms clarified. The importance of this is that, in such cases, it could always be claimed that analytic and synthetic forms differ radically in their syntactic structure, or in the morphosyntactic features involved in the two forms. The importance of the Latin perfect is that it presents a case in which the feature differentiating analytic from synthetic forms can be isolated and examined, and, as a result of this, it can be shown that the two types arise from the same syntactic structure.

A clear implication of the discussion presented here is in the domain of category. On the treatment of the perfect forms that is provided above, notions like morphological "adjective" and "verb" are epiphenomenal: they result from general properties of the language, statable in terms of syntactic structures. This does not mean that there are no syntactic categories; rather, it means that there is no simple and straight correspondence between lexical category labels like $\mathrm{N}, \mathrm{V}$, and A on both syntactic and morphological levels. What other features Roots may be specified for is still an open question. In any case the analysis highlights the nature of part-ofspeech labels by essentially dispensing with them. However, the treatment developed here is restricted to deverbal formations, where the effects of "category-changing" morphology are reduced to syntactic structures and postsyntactic morphological processes. The broader question, concerning whether all cases of derivational morphology can be analyzed without appeal to simple connections between syntactic categories and morphological category labels, is a matter for further research. 
The analysis also points to a connection between Roots and a feature that plays a role in the syntax. The implication of this part of the discussion is that a simple model of syntax/morphology interactions, in which Roots cannot be associated with syntactic features inherently, cannot be maintained. What remains to be seen is if this case fits with others crosslinguistically. For the time being, however, it provides a clear instance in which features associated arbitrarily with certain Roots have an effect that is not merely morphological. This points to a further set of questions regarding the hypothesis that Roots are subject to Late Insertion into syntactic structures, and regarding the relationships between features in syntax and morphology, questions that cut across several components of the grammar. One of the solutions advanced above is one in which the features of certain Roots are visible in the syntactic derivation, and in which this is so because certain Roots must be present in the syntax to begin with. Whether or not this solution is the best one depends upon the resolution of a host of issues that are only now becoming clear. The suggestion in light of this was that in order for the properties of Roots that are visible in the syntax to be identified exactly, the working hypothesis should be that no Root features are syntactically active, unless an argument to the contrary can be produced.

\section{References}

Allen, Joseph H. 1931. Allen and Greenough's new Latin grammar for schools and colleges. New York: Ginn.

Anderson, Stephen. 1982. Where's morphology? Linguistic Inquiry 13:571-612.

Anderson, Stephen. 1986. Disjunctive ordering in inflectional morphology. Natural Language \& Linguistic Theory 4:1-32.

Anderson, Stephen. 1992. A-morphous morphology. Cambridge: Cambridge University Press.

Aronoff, Mark. 1994. Morphology by itself: Stems and inflectional classes. Cambridge, Mass.: MIT Press. Arregi, Karlos. 1999. Tense in Basque. Ms., MIT, Cambridge, Mass.

Baldi, Phillip. 1976. Remarks on the Latin r-form verbs. Zeitschrift für vergleichende Sprachforschung 90: 222-257.

Beard, Robert. 1966. The affixation of adjectives in contemporary literary Serbo-Croatian. Doctoral dissertation, University of Michigan, Ann Arbor.

Beard, Robert. 1995. Lexeme-morpheme based morphology: A general theory of inflection and word formation. Albany: State University of New York Press.

Belletti, Adriana, and Luigi Rizzi. 1988. Psych-verbs and $\theta$-theory. Natural Language \& Linguistic Theory 6:291-352.

Benveniste, Émile. 1948. Noms d'agent et noms d'action en Indo-Européen. Paris: Adrien-Maisonneuve.

Binnick, Robert I. 1991. Time and the verb. Oxford: Oxford University Press.

Bobaljik, Jonathan. 1994. What does adjacency do? In MIT working papers in linguistics 21: The morphologysyntax connection, 1-32. MITWPL, Department of Linguistics and Philosophy, MIT, Cambridge, Mass.

Bobaljik, Jonathan. 1995. Morphosyntax: On the syntax of verbal inflection. Doctoral dissertation, MIT, Cambridge, Mass.

Bonet, Eulàlia. 1991. Morphology after syntax: Pronominal clitics in Romance. Doctoral dissertation, MIT, Cambridge, Mass.

Börjars, Kersti, Nigel Vincent, and Carol Chapman. 1996. Paradigms, periphrases, and pronominal inflection: A feature-based account. Yearbook of Morphology 1996, 155-180. 
Brugmann, Karl. 1895. Die mit dem Suffix -to- gebildeten Partizipia im Verbalsystem des Lateinischen und des Umbrisch-Oskischen. Indogermanische Forschungen 5:89-153.

Carstairs, Andrew. 1987. Allomorphy in inflexion. London: Croom Helm.

Carstairs-McCarthy, Andrew. 1992. Morphological theory. London: Routledge.

Chantraine, Pierre. 1927. Histoire du parfait grec. Paris: H. Champion.

Chomsky, Noam. 1970. Remarks on nominalization. In Readings in English transformationalgrammar, ed.

Roderick Jacobs and Peter Rosenbaum, 184-221. Waltham, Mass.: Ginn.

Chomsky, Noam. 1995. The Minimalist Program. Cambridge, Mass.: MIT Press.

Chomsky, Noam. 1998. Minimalist inquiries: The framework. (MIT Occasional Papers in Linguistics 15.) MITWPL, Department of Linguistics and Philosophy, MIT, Cambridge, Mass. [To appear in Step by step, ed. Roger Martin, David Michaels, and Juan Uriagereka. Cambridge, Mass.: MIT Press.]

Di Sciullo, Anna Maria, and Edwin Williams. 1987. On the definition of word. Cambridge, Mass.: MIT Press.

Draeger, Anton. 1878. Historische Syntax der lateinischen Sprache. Leipzig: B. G. Teubner.

Dubinsky, Stanley, and Silvester Ron Simango. 1996. Passive and stative in Chichewa: Evidence for modular distinctions in grammar. Language 72:749-781.

Elbourne, Paul. 1999. Some correlations between semantic plurality and quantifier scope. Paper presented at NELS 29 [to appear in the proceedings].

Embick, David. 1997. Voice and the interfaces of syntax. Doctoral dissertation, University of Pennsylvania, Philadelphia.

Embick, David. 1998. Voice systems and the syntax/morphology interface. In MIT working papers in linguistics 32: Papers from the UPenn/MIT Roundtable on Argument Structure and Aspect, 41-72. MITWPL, Department of Linguistics and Philosophy, MIT, Cambridge, Mass.

Embick, David, and Morris Halle. 1999. The Latin conjugation. Ms., MIT, Cambridge, Mass.

Embick, David, and Rolf Noyer. 1999. Locality in post-syntactic operations. In MIT working papers in linguistics 34: Papers in morphology and syntax, cycle two, 265-317. MITWPL, Department of Linguistics and Philosophy, MIT, Cambridge, Mass.

Ernout, Alfred. 1952/1989. Morphologie historique du latin. 4th ed. Paris: Klincksieck.

Ernout, Alfred, and François Thomas. 1951. Syntaxe latine. Paris: Klincksieck.

Flobert, Pierre. 1975. Les verbes déponents latins des origines à Charlemagne. Paris: Belles Lettres.

Gellius, Aulus. 1927. The Attic nights of Aulus Gellius, with an English translation by John C. Rolfe. London: W. Heinemann.

Gildersleeve, Basil, and Gonzalez Lodge. 1895. Latin grammar. London: Macmillan.

Giorgi, Alessandra, and Fabio Pianesi. 1991. Toward a syntax of temporal representations. Probus 3:187-213.

Giorgi, Alessandra, and Fabio Pianesi. 1997. Tense and aspect: From semantics to morphosyntax. Oxford: Oxford University Press.

Glare, P. G. W. 1982. Oxford Latin dictionary. Oxford: Oxford University Press.

Gonda, Jan. 1960a. Reflections on the Indo-European medium I. Lingua 9:30-67.

Gonda, Jan. 1960b. Reflections on the Indo-European medium II. Lingua 9:175-193.

Hale, Kenneth, and Samuel Jay Keyser. 1993. On argument structure and the lexical expression of syntactic relations. In The view from Building 20: Essays in linguistics in honor of Sylvain Bromberger, ed. Kenneth Hale and Samuel Jay Keyser, 53-109. Cambridge, Mass.: MIT Press.

Halle, Morris. 1990. An approach to morphology. In NELS 20, 150-184. GLSA, University of Massachusetts, Amherst.

Halle, Morris. 1997. Distributed Morphology: Impoverishment and fission. In MIT working papers in linguistics 30: Papers at the interface, 425-449. MITWPL, Department of Linguistics and Philosophy, MIT, Cambridge, Mass. 
Halle, Morris, and Alec Marantz. 1993. Distributed Morphology and the pieces of inflection. In The view from Building 20: Essays in linguistics in honor of Sylvain Bromberger, ed. Kenneth Hale and Samuel Jay Keyser, 111-176. Cambridge, Mass.: MIT Press.

Halle, Morris, and Alec Marantz. 1994. Some key features of Distributed Morphology. In MIT working papers in linguistics 21: Papers on phonology and morphology, 275-288. MITWPL, Department of Linguistics and Philosophy, MIT, Cambridge, Mass.

Harley, Heidi. 1995. Subjects, events, and licensing. Doctoral dissertation, MIT, Cambridge, Mass.

Harley, Heidi, and Rolf Noyer. 1998. Licensing in the non-lexicalist lexicon: Nominalizations, vocabulary items and the encyclopaedia. In MIT working papers in linguistics 32: Papers from the UPenn/MIT Roundtable on Argument Structure and Aspect, 119-138. MITWPL, Department of Linguistics and Philosophy, MIT, Cambridge, Mass.

Hofmann, Johann Baptist, Manu Leumann, and Anton Szantyr. 1963. Lateinische Grammatik, auf der Grundlage des Werkes von Friedrich Stolz und Joseph Hermann Schmalz: 2. Band Lateinische Syntax und Stilistik. Munchen: Beck'sche Verlagsbuchhandlung

Hovdhaugen, Even. 1987. Genera verborum quot sunt? Observations on the Roman grammatical tradition. In The history of linguistics in the classical period, ed. Daniel J. Taylor, 133-147. Amsterdam: John Benjamins.

Iatridou, Sabine. 1990. About Agr(P). Linguistic Inquiry 21:551-577.

Ippolito, Michela. 1999. On the past participle morphology in Italian. In MIT working papers in linguistics 34: Papers in morphology and syntax, cycle one, 111-138. MITWPL, Department of Linguistics and Philosophy, MIT, Cambridge, Mass.

Joffre, Marie-Dominique. 1986. La signification temporelle et aspectuelle d l'adjectif en -*to: Réflexions sur l'intégration d'une forme adjective au paradigme verbal. Revue des Études Latines 64:211-222.

Kemmer, Suzanne. 1993. The middle voice. Amsterdam: John Benjamins.

Kemmer, Suzanne. 1994. Middle voice, transitivity, and the elaboration of events. In Voice: Form and function, ed. Barbara Fox and Paul J. Hopper, 179-230. Amsterdam: John Benjamins.

Kiparsky, Paul. 1982. Lexical morphology and phonology. In Linguistics in the morning calm, ed. Linguistic Society of Korea, 3-91. Seoul: Hanshin.

Klaiman, Miriam H. 1991. Grammatical voice. Cambridge: Cambridge University Press.

Kratzer, Angelika. 1993. The event argument and the semantics of voice. Ms., University of Massachusetts, Amherst.

Leumann, Manu, Johann Baptist Hofmann, and Anton Szantyr. 1963. Lateinische Grammatik, auf der Grundlage des Werkes von Friedrich Stolz und Joseph Hermann Schmalz: 1. Band Lateinische Laut- und Formenlehre. München: Beck'sche Verlagsbuchhandlung.

Levin, Beth, and Malka Rappaport. 1986. The formation of adjectival passives. Linguistic Inquiry 17: 623-661.

Levin, Beth, and Malka Rappaport-Hovav. 1995. Unaccusativity: At the syntax-lexical semantics interface. Cambridge, Mass.: MIT Press.

Lidz, Jeffrey. 1998. Valency in Kannada: Evidence for interpretive morphology. In UPenn working papers in linguistics 5.2, 37-63. Penn Linguistics Club, University of Pennsylvania, Philadelphia.

Lieber, Rochelle. 1980. The organization of the lexicon. Doctoral dissertation, MIT, Cambridge, Mass.

Lindsay, William M. 1915. A short historical Latin grammar. Oxford: Oxford University Press.

Marantz, Alec. 1984. On the nature of grammatical relations. Cambridge, Mass.: MIT Press.

Marantz, Alec. 1988. Clitics, Morphological Merger, and the mapping to phonological structure. In Theoretical morphology, ed. Michael Hammond and Michael Noonan, 253-270. San Diego, Calif.: Academic Press.

Marantz, Alec. 1989. Projection vs. percolation in the syntax of synthetic compounds. In Selected papers from the Annual Spring Colloquium, 95-112. UNC Linguistics Circle, University of North Carolina, Chapel Hill. 
Marantz, Alec. 1994. A late note on Late Insertion. Ms., MIT, Cambridge, Mass.

Marantz, Alec. 1995. "Cat" as a phrasal idiom: Consequences of Late Insertion in Distributed Morphology. Ms., MIT, Cambridge, Mass.

Marantz, Alec. 1997. No escape from syntax: Don't try morphological analysis in the privacy of your own lexicon. In Proceedings of the 21 st Penn Linguistics Colloquium, 201-225. UPenn Working Papers in Linguistics, University of Pennsylvania, Philadelphia.

Matthews, Peter H. 1972. Inflectional morphology: A theoretical study based on aspects of Latin verb conjugation. Cambridge: Cambridge University Press.

McCartney, Eugene S. 1926. Makeshifts for the passive of deponent verbs in Latin. Philological Quarterly 5:289-298.

McGinnis, Martha. 1998. Morphological “anaphora” as syntactic movement. Ms., University of Pennsylvania, Philadelphia.

Meillet, Antoine. 1966. Esquisse d'une histoire de la langue latine. Paris: Klincksieck.

Nölting, Theodor. 1859. Über das lateinische Deponens. Wismar.

Noyer, Rolf. 1992. Features, positions, and affixes in autonomous morphological structure. Doctoral dissertation, MIT, Cambridge, Mass.

Noyer, Rolf. 1997. Features, positions and affixes in autonomous morphological structure. New York: Garland.

Noyer, Rolf. 1998. Impoverishment theory and morphosyntactic markedness. In Morphologyand its relation to syntax and phonology, ed. Steven Lapointe, Diane Brentari, and Patrick Farrell, 264-285. Stanford, Calif.: CSLI Publications. [Distributed by Cambridge University Press.]

Oltra, Maria Isabel. 1999. On the notion of theme vowel: A new approach to Catalan verbal morphology. Master's thesis, MIT, Cambridge, Mass.

Pesetsky, David. 1995. Zero syntax: Experiencers and cascades. Cambridge, Mass.: MIT Press.

Pollock, Jean-Yves. 1989. Verb movement, Universal Grammar, and the structure of IP. Linguistic Inquiry 20:365-424.

Sauerland, Uli. To appear. Scope reconstruction without reconstruction. In Proceedings of the 17th West Coast Conference on Formal Linguistics. Stanford, Calif.: CSLI Publications.

Serbat, Guy. 1980. Le parfait de l'indicatif actif. In Le sens du parfait de l'indicatif actif en latin, ed. Guy Serbat, 1-33. Colloque de Morigny, Université de Paris IV Sorbonne.

Sicking, C. M. J., and Peter Stork. 1996. The synthetic perfect in classical Greek. In Two studies in the semantics of the verb in classical Greek, ed. C. M. J. Sicking and Peter Stork, 119-298. Leiden: E. J. Brill.

Sihler, Andrew L. 1995. New comparative grammar of Greek and Latin. New York: Oxford University Press.

Sobin, Nicholas. 1985. Case assignment in Ukrainian morphological passive constructions.Linguistic Inquiry 16:649-662.

Sommer, Ferdinand. 1914. Handbuch der lateinischen Laut- und Formenlehre. Heidelberg: Carl Winters Universitätsbuchhandlung.

Varro, Marcus Terentius. 1938. On the Latin language, with an English translation by Roland G. Kent. Cambridge, Mass.: Harvard University Press.

Wackernagel, Jakob. 1904. Studien zum griechischen Perfektum. In Kleine Schriften Band II. Göttingen: Vandenhoeck and Rupprecht.

Wackernagel, Jakob. 1920. Vorlesungen über Syntax, mit besonderer Berücksichtigung von Griechisch, Lateinisch, und Deutsch. Basel: Philologischen Seminar der Universität Basel.

Wasow, Thomas. 1977. Transformations and the lexicon. In Formal syntax, ed. Peter Culicover, Thomas Wasow, and Adrian Akmajian, 327-360. New York: Academic Press. 


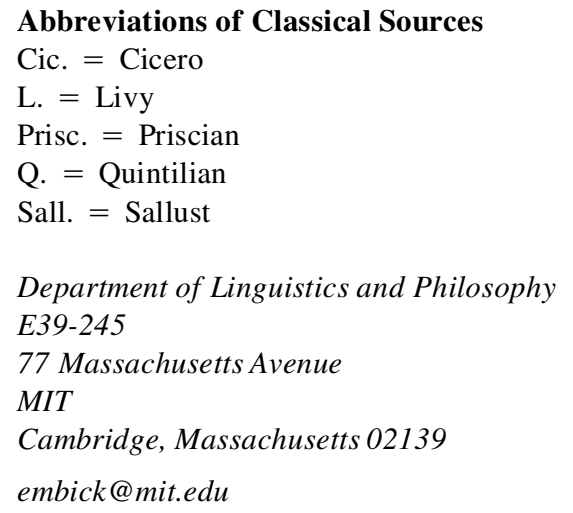

